\title{
Computational perspectives revealed prospective vaccine candidates from five structural proteins of Novel SARS Corona Virus 2019 (SARS-CoV-2)
}

\author{
Rajesh Anand $^{\text {Corresp., Equal first author, } 1 \text {, Subham Biswal }}{ }^{\text {Equal first author, } 1}{ }^{\text {, Renu Bhatt }}{ }^{1}$, Bhupendra N Tiwary ${ }^{1}$ \\ ${ }^{1}$ Department of Biotechnology, Guru Ghasidas Vishwavidyalaya, (A Central University), Bilaspur, Chhattisgarh, India \\ Corresponding Author: Rajesh Anand \\ Email address: rajesh9in@gmail.com
}

Background. The present pandemic COVID-19 is caused by SARS-CoV-2, a Single Stranded positive sense RNA virus from Coronaviridae family. Due to lack of antiviral drugs, vaccine against the virus is urgently required. Methods. In this study, validated computational approaches were used to identify peptide based epitopes from six structural proteins having antigenic properties. The Net-CTL 1.2 tool was used for the prediction of $\mathrm{CD}^{+} \mathrm{T}$-cell epitopes, while the robust tools Bepi-Pred 2 and LBtope was employed for the identification of linear B-cell epitopes. Docking studies of the identified epitopes were performed using HADDOCK 2.4 and the structures were visualized by Discovery Studio and LigPlot $^{+}$. Antigenicity, immunogenicity, conservancy, population coverage and allergenicity of the predicted epitopes were determined by the bioinformatics tools like VaxiJen v2.0 server, the Immune Epitope Database (IEDB) tools and AllerTOP v.2.0,AllergenFP 1.0 and ElliPro. Results. The predicted T cell and linear B-cell epitopes were considered as prime vaccine targets in case they passed the requisite parameters like antigenicity, immunogenicity, conservancy, non-allergenicity and broad range of population coverage. Among the predicted CD8 $+\mathrm{T}$ cell epitopes, potential vaccine targets from surface glycoprotein were; YQPYRVVVL, PYRVVVLSF, GVYFASTEK, QLTPTWRVY, and those from ORF3a protein were LKKRWQLAL, HVTFFIYNK. Similarly RFLYIIKLI, LTWICLLQF from membrane protein and three epitopes viz; SPRWYFYYL, TWLTYTGAI, KTFPPTEPK from nucleocapsid phosphoprotein were the superior vaccine targets observed in our study. The negative values of HADDOCK and $Z$ scores obtained for the best cluster indicated the potential of the epitopes as suitable vaccine candidates. Analysis of the 3D and 2D interaction diagrams of best cluster produced by HADDOCK 2.4 displayed the binding interaction of leading T cell epitopes within the MHC-1 peptide binding clefts. On the other hand, among linear B cell epitopes majority of potential vaccine targets were from 
HGKEDLKFPRGQGVPINTNSSPDDQIGYYRRATRRIRGGDGKMKDLS ${ }^{-105},{ }^{227}$ LNQLE SKMSGKGQQQQGQTVTKKSAAEASKKPRQKRTATKK ${ }^{-266},{ }^{3-D N G P Q N Q R N A P R I T F G G P}{ }^{-20}, 29$ -

GERSGARSKQRRPQGL ${ }^{-45}$. Other two prime vaccine targets; ${ }^{370-}$

NSASFSTFKCYGVSPTKLNDLCFTNVV ${ }^{-395}$ and ${ }^{260-}$ AGAAAYYVGYLQPRT ${ }^{-274}$ was identified in the spike protein. The potential B-cell conformational epitopes were predicted on the basis of higher protrusion index indicating greater solvent accessibility. These conformational epitopes were of various lengths and belonged to spike, ORF3a, membrane and nucleocapsid proteins. Conclusions. Taken together, eleven T cell epitopes, seven B cell linear epitopes and ten $B$ cell conformational epitopes were identified from five structural proteins of SARS-CoV-2 using advanced computational tools. These potential vaccines candidates may provide important timely directives for effective vaccine against SARSCoV-2. 
1 Computational perspectives revealed prospective vaccine candidates from five structural

2 proteins of Novel SARS Corona Virus 2019 (SARS-CoV-2)

3 Rajesh Anand ${ }^{1 \#}$ Subham Biswal \#, Renu Bhatt, Bhupendra N. Tiwary

4 Department of Biotechnology, Guru Ghasidas Vishwavidyalaya (A Central University),

5 Bilaspur, Chhattisgarh, India

6

7 Corresponding Author: Rajesh Anand ${ }^{1}$

8 Department of Biotechnology, Guru Ghasidas Vishwavidyalaya (A Central University),

9 Bilaspur, Chhattisgarh, India

10 Email address: rajesh9in@gmail.com

11 \# Authors contributed equally to the research work

12

\section{Abstract}

Background. The present pandemic COVID-19 is caused by SARS-CoV-2, a Single Stranded positive sense RNA virus from Coronaviridae family. Due to lack of antiviral drugs, vaccine against the virus is urgently required.

Methods. In this study, validated computational approaches were used to identify peptide based epitopes from six structural proteins having antigenic properties. The Net-CTL 1.2 tool was used for the prediction of $\mathrm{CD} 8^{+} \mathrm{T}$-cell epitopes, while the robust tools Bepi-Pred 2 and LBtope was employed for the identification of linear B-cell epitopes. Docking studies of the identified epitopes were performed using HADDOCK 2.4 and the structures were visualized by Discovery Studio and LigPlot ${ }^{+}$. Antigenicity, immunogenicity, conservancy,population coverage and allergenicity of the predicted epitopes were determined by the bioinformatics tools like VaxiJen v2.0 server, the Immune Epitope Database (IEDB) tools and AllerTOP v.2.0,AllergenFP 1.0 and ElliPro.

Results. The predicted $\mathrm{T}$ cell and linear B-cell epitopes were considered as prime vaccine targets in case they passed the requisite parameters like antigenicity, immunogenicity, conservancy, non-allergenicity and broad range of population coverage. Among the predicted CD8+ T cell epitopes, potential vaccine targets from surface glycoprotein were; YQPYRVVVL, PYRVVVLSF, GVYFASTEK, QLTPTWRVY, and those from ORF3a protein were LKKRWQLAL, HVTFFIYNK. Similarly RFLYIIKLI, LTWICLLQF from membrane protein and three epitopes viz; SPRWYFYYL, TWLTYTGAI, KTFPPTEPK from nucleocapsid phosphoprotein were the superior vaccine targets observed in our study. The negative values of HADDOCK and $\mathrm{Z}$ scores obtained for the best cluster indicated the potential of the epitopes as suitable vaccine candidates. Analysis of the 3D and 2D interaction diagrams of best cluster produced by HADDOCK 2.4 displayed the binding interaction of leading $\mathrm{T}$ cell epitopes within the MHC-1 peptide binding clefts. On the other hand, among linear B cell epitopes majority of potential vaccine targets were from nucleocapsid protein, viz; ${ }^{59-}$ HGKEDLKFPRGQGVPINTNSSPDDQIGYYRRATRRIRGGDGKMKDLS ${ }^{-105}$, 227 -LNQLE 
SKMSGKGQQQQGQTVTKKSAAEASKKPRQKRTATK ${ }^{-266},{ }^{3-D N G P Q N Q R N A P R I T F G G P-20, ~}$ ${ }^{29-G E R S G A R S K Q R R P Q G L}{ }^{-45}$. Other two prime vaccine targets; ${ }^{370-}$ NSASFSTFKCYGVSPTKLNDLCFTNV ${ }^{-395}$ and ${ }^{260-A G A A A Y Y V G Y L Q P R T-274 ~ w a s ~ i d e n t i f i e d ~}$ in the spike protein. The potential B-cell conformational epitopes were predicted on the basis of higher protrusion index indicating greater solvent accessibility. These conformational epitopes were of various lengths and belonged to spike, ORF3a, membrane and nucleocapsid proteins. Conclusions. Taken together, eleven T cell epitopes, seven B cell linear epitopes and ten B cell conformational epitopes were identified from five structural proteins of SARS-CoV-2 using advanced computational tools. These potential vaccines candidates may provide important timely directives for effective vaccine against SARS-CoV-2.

\section{Introduction}

Globally the present dreaded pandemic of corona virus disease 2019 (COVID-19) has resulted in deaths of more than 445000 humans [World Health Organization (WHO) COVID-2019-situation report-150]. The causative agent of the disease has been severe acute respiratory syndrome corona virus 2 (SARS-CoV-2) [Corona virus disease 2019-WHO]. The family Coronaviridae consists of a large group of viruses known as Corona viruses (CoVs). The corona viruses were thought to be harmless respiratory human pathogens due to (i) harmless mild infections and (ii) limited number of the circulating viruses in humans [Song et al., 2019]. However, the emergence of series of three severe and fatal diseases caused by corona virus changed the concept. The first instance was severe acute respiratory syndrome (SARS) in November 2002 to Feb. 2003 in China and the second was Middle East Respiratory Syndrome (MERS) in June 2012 in Saudi Arabia [de Wit et al., 2016)]. The most recent cases of fatal disease outbreaks caused by corona virus occurred in December 2019, in Wuhan, Hubei, China. These consecutive viral outbreaks also indicate the threat of cross-species transmission of these viruses leading to severe infectious outbreak in humans that should be considered seriously [Menachery, V. D. et al., 2015]. Therefore, the threats of CoVs should not be undermined and the research on the life cycle and host-virus interactions should be advanced in order to develop treatments and vaccines against these viruses. The scientific and clinical investigations demonstrated that SARS-CoV and MERS-CoV share remarkable features that lead to preferential viral replication in the lower respiratory tract and viral immunopathology. The recent investigations on the clinical, laboratory, radiological and epidemiological characteristics and outcomes of treatments in patients demonstrated that the severe respiratory illness similar to SARS-CoV was due to SARSCoV-2 (COVID-19) [Huang et al., 2020]. Although the early investigations patterns suggested that the COVID-19 virus can cause severe illness in some patients, with limited transmission among people, up to date epidemiological data strongly favours the statement that the new virus has evolved/ adapted more efficiently for transmission among humans. The genome sequences of COVID-19 viruses obtained from patients indicated that they share $79.5 \%$ sequence identity to SARS-CoV [Zhou et al., 2020] and 96\% identity to bat corona virus at the whole genome level. The phylogenetic studies of corona viruses obtained from different organisms indicated that COVID-19 could have originated from Chinese horseshoe bats, however, the vehicle which led 
81 to the transmission to host has not yet been identified [Dong et al., 2020]. COVID-19 virus was

82 bannered as a novel type of corona virus from bat due to a high degree of variation from the 83 human SARS virus [Shereen et al., 2020; Andersen et al., 2020]. Altogether seven member of

84 the family of CoVs infect humans, the COVID-19 is the newest of all. Both SARS-Corona Virus 85 and COVID-19 virus enters host cells through an endosomal pathway and the cells through the 86 entry receptor, angiotensin-converting enzyme II (ACE2) [Zhou et al., 2020; Letko et al., 2020]. 87 The SARS-CoV and hCoV-NL63 utilizes human angiotensin converting enzyme 2 (ACE2) for 88 virus entry [Hofmann et al., 2005; Li et al., 2003; Wu et al., 2009]. Recently scientists have 89 determined that SARSCoV-2 also interacts with ACE2 for cell entry [Zhou et al., 2020]. The 90 entry process of corona viruses is facilitated by the surface-located spike glycoprotein [Lu et al., 91 2015]. Spike protein can be divided into the S1 and S2 subunits, which are utilized as receptor 92 recognition and membrane fusion molecules, respectively [Lai et al., 2007]. S1 Both the N93 terminal domain (NTD) and a C-terminal domain (CTD) of S1 unit can function as a receptor94 binding entity or receptor binding domain (RBD) [Li et al., 2005; Lu et al., 2013; Taguchi and 95 Hirai-Yuki, 2012]. Recently, the S1 CTD (SARS-CoV-2-CTD) has been identified as the prime 96 region in SARS-CoV-2 that interacts with the ACE2 receptor [Wang et al., 2020]. The crystal 97 structure of SARS-CoV2-CTD in complex with human ACE2, exhibited bindings similar to that 98 observed for the SARS-CoV-RBD. It has been further identified that SARS-CoV-2-CTD forms 99 more atomic interactions with human ACE2 than SARS-RBD, resulting in higher affinity for 100 receptor binding [Shang et al., 2020; Wang et al., 2020].

101 On the basis of the genetic properties, Coronaviridae family can be divided in to four genera, 102 including genus Alpha corona virus, genus Beta corona virus, genus Gamma corona virus, and 103 genus Delta corona virus. Among the RNA viruses, the corona virus has the largest genome 104 (ranging from 26 to $32 \mathrm{~kb}$ ) with particle size of viruses about $125 \mathrm{~nm}$ in diameter [ Ji et al., 105 2020]. CoVs possess a composite genome expression strategy as numerous CoV proteins 106 expressed in the infected cell contribute to the corona virus-host interactions. These strategies include (i) associations with the host cell to create a favorable environment for CoV replication, (ii) modification of the host gene expression and nullifying the antiviral defences of host. The CoV-host interplay is thus key to pathogenesis of virus [de Wilde et al., 2018]. Two-thirds of the $\mathrm{CoV}$ genome belongs to genes for non-structural proteins. Amid the structural proteins, spike $(\mathrm{S})$, envelope $(\mathrm{E})$, membrane $(\mathrm{M})$, and nucleocapsid $(\mathrm{N})$ can be considered important in terms of vaccine potential. The viral membrane has $\mathrm{S}, \mathrm{E}$, and $\mathrm{M}$ proteins. The Spike protein is a surfacelocated trimeric glycoprotein and actively plays a role in viral ingress into host cells, viral infection, and pathogenesis and was contemplated as a prime vaccine and therapeutic target against SARS-CoV and MERS-CoV. The membrane and envelope proteins are required in viral assemblage, whereas the nucleocapsid protein is involved for assembly of RNA genome [Song et 117 al., 2019].

118 Although CoVs share numerous resemblances, they also have genetically evolved significantly 119 and finding the potential targets for vaccines and antiviral drugs against COVID-19 should 120 exploit the structural similarities between SARS-CoV and COVID-19 virus and focus on 
121 proteins that are highly conserved across multiple CoVs. In this work all the structural proteins

122

123

124

125

126

127

128

129

130

131

132

133

134

135

136

137

138

139

140

141

142

143

144

145

146

147

148

149

150

151

152

153

154

155

156

157

158

159

160

were selected for finding the epitopes for designing the vaccine against CoVID-19 using validated in silico approaches.

\section{Materials \& Methods}

The overall procedures used in the present study for epitope-based vaccine design and physicochemical property prediction have been depicted in the form of flow chart (Fig.1).

Retrieval of the Protein Sequence: The protein sequences of SARS-CoV-2 were retrieved from the Virus Pathogen Database and Analysis Resource (ViPR) (http://www.viprbrc.org/) in FASTA format. ViPR database helps in fetching the sequence from both GenBank and UniProtKB in the FASTA format [Pickett et al., 2012]. The nonstructural proteins of SARSCoV-2 were removed from the complete proteome of SARS-CoV-2.

Similarity search and selection of protein for epitope prediction: The sequences of potential structural proteins (surface glycoprotein, orf3a protein, envelope protein, membrane glycoprotein, nucleocapsid phosphoprotein, orf6 protein) were searched for the similarity using the BLAST tool (https://blast.ncbi.nlm.nih.gov/Blast.cgi?PAGE=Proteins). Only those hits were selected for comparison of identities which showed $100 \%$ query cover. The BLAST results of surface glycoprotein (Accession No. QHQ82464) exhibited more than $99.84 \%$ identity (100 hits) and those of orf3a (Accession No.QHQ82465) showed identities of more than 99.27\% (74 hits). Next the envelope protein (Accession No.QHQ82466) resulted in 14 hits with the identity range between 100 to $94.67 \%$ while the BLAST using the membrane glyco-protein (Accession No. QHQ82467) resulted in about 50 hits with the range of identity between 100 to $93.24 \%$. Similarly the nucleocapsid phosphoprotein (Accession No.QHQ82471) resulted in 100 hits with identity in the range from 100 to $99.28 \%$. The last selected protein from SARS-CoV-2, orf6 (Accession No. QHQ82468) exhibited an identity range between 100 to $95 \%$ in more than 40 hits. Since all the BLAST searches performed using the above structural proteins demonstrated the identity between 93 to $100 \%$, a conclusion was drawn that any one representative protein from the six structural proteins could be used for further study. Thus we selected all the six complete sequences of proteins with the above accession numbers for further studies.

Determination of antigenicity of the SARS-CoV-2 MHC I epitopes: The term antigenicity is the capacity of a molecule to be specifically recognized by the antibodies generated as a result of immune response to the given substance. Proteins generated by divergent or convergent evolution may lack apparent sequence similarity, although they may share structural similarity and biological characteristics [Petsko \& Ringe, 2004]. Antigenicity may be encoded in a sequence in a fine and obscure manner not feasible to direct recognition by sequence alignment. Similarly, the search of novel antigens will be circumvented by their lack of similarity to antigens of known origin [Doytchinova and Flower 2007]. A novel alignment-free approach for antigen prediction, VaxiJen, based on auto cross covariance (ACC) transformation of protein sequences into uniform vectors of principal amino acid properties was developed to control the limitations of alignment based strategies [Doytchinova and Flower 2007]. All the structural proteins of SARS-CoV-2 were submitted to the VaxiJen v2.0 server (http://www.ddg-

Peer] reviewing PDF | (2020:04:47510:1:1:NEW 24 Jun 2020) 
161 pharmfac.net/vaxijen/VaxiJen/VaxiJen.html) [Doytchinova and Flower, 2007] in FASTA format 162 for the determination of antigenicity. A threshold value of 0.4 was considered for determination 163 of antigenicity.

164

\section{Prediction and identification of $\mathbf{T}$ Cell Epitopes}

167

168

The T-cell epitopes are usually small peptide fragments of 8-11 amino acids and can elicit specific immune responses. These are important for epitope-based peptide vaccine design [Patronov and Doytchinova, 2013]. The NetCTL 1.2 server (http://www.cbs.dtu.dk/services/NetCTL/), can be utilized for the prediction of the T cell epitopes in any specified protein. The server can anticipate the epitope for $12 \mathrm{MHC}$-I super types A1, A2, A3, A24, A26, B7, B8, B27, B39, B44, B58, B62 present on CD8 ${ }^{+}$T Cells. The prediction of epitope of $\mathrm{CD}^{+} \mathrm{T}$ cell is on the basis of interpretations obtained from proteasomal $\mathrm{C}$ terminal cleavage, MHC class I binding, and TAP transport efficiency. The artificial neural network (ANN) is used for the prediction of MHC class I binding, proteasomal C terminal cleavage, while weight matrix is employed for the estimation of TAP transport efficiency [Larsen et al., 2005; Larsen et al., 2007]. In this study the server was used for the prediction of epitopes of all the 12 super types of MHC I and a higher threshold value of 1.25 for epitope prediction was fixed, which has a better sensitivity and specificity of 0.54 and 0.993 , respectively. The default parameters set by server for the weight matrix determination for proteasomal $\mathrm{C}$ terminal cleavage $(0.15)$ and TAP transport efficiency $(0.05)$ were used.

\section{Prediction of Antigenicity}

For the recognition of both frequently and non-frequently occurring MHC-I-binding alleles, the T cell epitopes of SARS-CoV-2 were analyzed by the stabilized matrix base method (SMM) of the IEDB analysis tool (http://tools.iedb.org/mhci/) as described earlier [Peters et al., 2005; Lundegaard et al, 2008]. The recognition of MHC-I binding alleles were performed on the parameters (i) the peptide length of epitope was restricted to 9 and (ii) the IC50 of less than 250 $\mathrm{nM}$ was selected on the server. Lower IC50 value signifies higher binding. The HLA-binding affinity of the epitopes is quantitatively described in the IC50 nM units. In general, for similar ligands, higher binding affinity of the epitopes with the MHC class I molecule is reflected by the lower IC50 value. Therefore, IC50 values less than 250nM (IC50<250) was selected for ensuring higher binding affinity of the epitopes. The IC50 of the epitopes were determined by the IEDB tool. IEDB being a resourceful server, can also be used for the estimation of processing score, TAP score, proteasomal cleavage, and the MHC-I binding score of the specified epitopes and their respective alleles using the stabilized matrix based method [Peters et al.,2003; Tenzer et al., 2005]. Epitopes were selected based on the highest combined score, but the final selection for further study was made after the prediction of antigenicity by VaxiJen v2.0 server and that of immunogenicity by IEDB server. The combined score is the derived from median percentile rank of seven alleles and immunogenicity score using following equation 
201 Percentile rank of seven alleles), where alpha is optimized to 0.4 as described earlier [Dhanda et 202 al., 2018].

203 Epitope Immunogenicity and Conservancy Prediction

204 Immunogenicity is defined as the ability of a substance/molecule to instigate cellular and 205 humoral immune response [Ilinskaya and Dobrovolskaia, 2016]. Conservancy may be defined 206 as the fragment of protein sequences that carry the epitope which is considered at or above a 207 specified level of identity [Bui et al., 2007]. The effective T-cell epitopes are more immunogenic 208 and are considered better than the less immunogenic peptides [Adhikari et al., 2018]. Therefore, 209 the epitope with better immunogenicity was selected for further evaluation. The immunogenicity 210 prediction tool available on the server http://tools.iedb.org/immunogenicity/ was utilized for the 211 identification of immunogenicity while conservancy was predicted by the tool available on iedb 212 (http://tools.iedb.org/conservancy/) [Nielsen et al., 2007; Calis et al., 2013]. All the epitopes

213 having positive immunogenicity scores (given by IEDB tool) were considered a potential 214 immunogen.

215 Determination of population coverage

216 MHC molecules are exceptionally polymorphic and more than a thousand divergent human 217 MHC (HLA) alleles are recognized. To determine the population coverage a tool is required that 218 can optimally calculate the distribution of humans which will respond to a given group of 219 epitope on the basis of HLA genotypic prevalence and MHC binding and/or T cell restriction 220 data [Bui et al., 2007]. Population coverage for each identified epitope and their corresponding 221 MHC HLA-binding alleles was determined by the population coverage tool available on IEDB 222 server (http://tools.iedb.org/population/). Here we used the allelic frequency of the interacting 223 HLA alleles for the prediction of the population coverage for the corresponding epitope. In a 224 recent report population coverage of about $64 \%$ was reported for an epitope [Oany et al., 225 2014].In this study a population coverage of $65 \%$ or more was selected.

226 Allergenicity and Toxicity assessment

227 The web-based AllerTOP v.2.0 (http://www.ddg-pharmfac.net/AllerTOP/) [Dimitrov et al., 228 2014] and AllergenFP 1.0 (http://www.ddg-pharmfac.net/AllergenFP/) [Dimitrov et al., 2014a] 229 was used to check the allergenicity of our proposed epitope for vaccine development. AllergenFP 2301.0 has been established on a novel alignment-free descriptor-based fingerprint technique. An 231 accuracy of $87.9 \%$ is observed in the identification of both allergens and nonallergens by 232 AllergenFP 1.0. In contrast, to classify allergens and nonallergens, AllerTOP v. 2.0 has been 233 established on the basis of $k$-nearest neighbours $(\mathrm{kNN})$ method. The web server ToxinPred 234 (http://crdd.osdd.net/raghava/toxinpred/) was implemented to predict toxicity of the peptides 235 [Gupta et al., 2013]. This strategy was developed the basis of machine learning technique and 236 quantitative matrix utilizing distinctive properties of peptides.

237 Prediction of MHC II epitopes:

238 The disadvantage of many bioinformatics methods including Gibbs samplers, Ant colony, 239 Artificial neural networks, Support vector machines, hidden Markov models, and motif search 240 algorithms for predicting MHC class II epitopes is owing to training and evaluation on very 
241 limited data sets covering a single or a few different MHC class II alleles [Nielsen et al., 2007].

242 On the IEDB database, a large group of quantitative MHC class II peptide-binding data is

243 available [Toseland et al., 2005]. The data includes the peptide with binding affinities (IC50) for

244 more than $14 \mathrm{HLA} / \mathrm{MHC}$. A novel stabilized matrix method (SMM)-align method (NetMHCII)

245 for quantitative predictions of MHC class II binding was developed which utilizes the IEDB

246 MHC class II peptide binding database [Nielsen et al., 2007]. The SMM-align method attempts

247 to recognize a weight matrix that ideally emulates the measured IC50 values for each peptide in

248 the training group [Nielsen et al., 2007]. The MHC I epitopes derived from structural proteins

249 were selected for the prediction of MHC-II-binding alleles using the SMM-align method. As per

250 the instruction of the tool, an IC 50 value up to $3000 \mathrm{nM}$ was considered significant.

251 Design of the three-dimensional (3D) structure of epitope

252 In order to be considered as proper vaccine candidate, an epitope need to fulfill all the criteria

253 like antigenicity, immunogenicity, conservancy of epitopes, non-toxicity and it should be non-

254 allergen. Epitope candidates were evaluated on the basis of above parameters and were subjected

255 to the determination of three-dimensional structure using the PEP-FOLD peptide prediction

256 server (http://bioserv.rpbs.univ-paris-diderot.fr/services/PEP-FOLD/) [Thévenet et al., 2012;

257 Shen et al., 2014]. Thus the potential epitopes fulfilling all the above criteria were used for the

258 structure determination. The best model obtained using the server was taken forward for docking

259 analysis.

260 Docking analysis

261 To know the binding interactions between HLA molecules and the predicted epitope, molecular

262 docking simulation was executed using High Ambiguity Driven protein-protein DOCKing

263 (HADDOCK) version: 2.4 (https://bianca.science.uu.nl/haddock2.4/). HADDOCK is an

264 information-driven flexible docking approach for the modeling of biomolecular complexes.

265 Despite continuous advances in the field, the accuracy of ab initio docking-without using any

266 experimental restraints-remains generally low [Huang, 2015]. Data-driven approaches such as

267 HADDOCK [Van Zundert et al., 2015], which integrate information derived from biochemical,

268 biophysical or bioinformatics methods to enhance sampling, scoring or both [Rodrigues and

269 Bonvin, 2014], perform remarkably better. The main attribute of HADDOCK is the Ambiguous

270 Interaction Restraints or AIRs. These permit the conversion of raw data including mutagenesis

271 experiments or NMR chemical shift perturbation into distance restraints which are integrated in

272 the energy functions. These energy functions are used in calculations. In the docking protocol of

273 HADDOCK, molecules pass through varying degrees of flexibility and distinct chemical

274 surroundings [Van Zundert et al., 2015].

275 The performance of HADDOCK protocol depends on the number of models generated at each

276 step. The grading of the clusters is based on the average score of the top 4 members of each

277 cluster. The score is calculated as:

278 HADDOCK score $=1.0 *$ Evdw $+0.2 *$ Eelec $+1.0 *$ Edesol $+0.1 *$ Eair 
279 Where, "Evdw" represents the intermolecular van der Waals energy, "Eelec" is the

280 intermolecular electrostatic energy, where as "Edesol" is an empirical desolvation energy

281 [Fernandez-Recio et al., 2004], and Eair represents the AIR energy.

282 Numbering of cluster in the results indicates the magnitude of the cluster. The diverse elements

283 of the HADDOCK score are also described for each cluster on the results web page. The top

284 cluster is the most reliable according to HADDOCK. The more negative results of HADDOCK

285 score and $\mathrm{Z}$ score signifies better structures and interaction [HADDOCK 2.4 basic protein-

286 protein docking tutorial].

287 For the HADDOCK inputs, the crystal structure of the HLA-C*07:02 (PDB id: 5VGE) HLA-

288 A*30:01 (6J1W), HLA-B*58:01, (5VWH), HLA-B*08:01, (3X13) was retrieved from the RCSB

289 Protein Data Bank (PDB) in the PDB format [Gras et al., 2010]. PyMol (Version-2.3.4) was used

290 to remove water and for the retrieval of different chains of HLA allele from the crystal structure,

291 which was in a complex form with protein and a peptide [PyMOL]. The structure of chain A

292 having the peptide binding cleft was then directly submitted on the HADDOCK 2.4 as protein

293 molecule while PEPFOLD derived structures of predicted epitopes were used as ligands. After

294 registration "easy interface" was selected for docking. In the docking parameter section default

295 parameter was selected. The default parameters can be found on the haddock server website

296 https://wenmr.science.uu.n1/haddock2.4/settings.

297 Similarly for MHC II epitopes, the crystal structures of HLA-DRB1*01:01 (PDB id:2FSE), 298 HLA-DRB1*01:01 (2FSE) HLA-DRB1*04:01 (5LAX) were retrieved from PDB. PyMOL was

299 used for removing water and the structures of chain A and B were derived to be submitted at

300 HADDOCK as protein molecule. Other procedures similar to MHC I were also followed for

301 docking of MHC II alleles and predicted epitopes.

302 The 3D structures of the best cluster obtained from the HADDOCK results were visualized using

303 PyMOL (Version-2.3.4). For 2D interaction studies the Discovery studio visualizer (Version:

304 v20.1.0.19295) was used for the MHC I epitopes [Dassault Systèmes, 2020], on the other hand

305 LigPlot + (Version: Ligplot+ v.1.4.5) was used for the MHC II epitopes [Wallace et al., 1995 ].

306 LigPlot was used for MHC II epitopes as the discovery studio visualize has a limit of 1000 atoms

307 for epitope.

308 Re-docking and Validation of the Docking Methods: For validating docking methodologies

309 the crystal structure of HLA molecules and the corresponding epitope as available in the PDB

310 were selected for re-docking. The crystal structures of the following PDB IDs (i) 5VGE (ii)

$3116 \mathrm{~J} 1 \mathrm{~W}$ (iii) $5 \mathrm{VWH}$ (iv) $3 \mathrm{X} 13$, (v) $3 \mathrm{C} 9 \mathrm{~N}$ (vi) $2 \mathrm{FSE}$ and (vii) $5 \mathrm{LAX}$ were taken. Then the

312 structures of the HLA molecules and the corresponding peptide were retrieved by using

313 PYMOL. The chain ' $A$ ' for MHC I allele and chains ' $A$ ' and ' $B$ ' from MHC II allele were

314 submitted as protein molecules as done for the predicted epitope dockings above. In the re-

315 docking, however, the peptides derived from the above crystal structures were used as ligands. In

316 the next steps all the above procedures used for the predicted MHC I and MHC II epitope

317 docking (HADDOCK 2.4 protocol) were followed for re-docking and the best cluster structures

318 were visualized using PYMOL and Discovery Studio/ LIGPLOT+. 


\section{Identification of the B cell epitope}

320 The optimum B-cell epitope identification is the crucial step for epitope-based vaccine design.

321

322

323

324

325

326

327

328

329

330

331

332

333

334

335

336

337

338

339

340

341

342

343

344

345

346

347

348

349

350

351

352

353

354

355

356

357

The B-cell epitopes were recognized from the SARS-CoV-2 proteins utilizing the web based server BepiPred-2.0 (http://www.cbs.dtu.dk/services/BepiPred/) [Jespersen et al., 2017] and LBtope methods (http://crdd.osdd.net/raghava//lbtope/) [Singh et al., 2013]. BepiPred-2.0 might be viewed as the prime and up-to-date B-cell epitope prediction strategy as it exhibit remarkable solution on both epitope data obtained from a vast number of linear epitopes taken from the IEDB database and on structural data of epitope derived from crystallography studies. LBtope is other robust tool for linear B-cell epitope prediction. It was developed on the basis of experimentally proven non B-cell epitopes derived from IEDB database.

The ElliPro (http://tools.iedb.org/ellipro/) tool was used for the prediction of conformational or discontinuous B-cell epitopes [Ponomarenko et al., 2008]. ElliPro is considered as most comprehensive method that can identify both the conformational and linear epitopes on the basis of 3-dimensional structure and provides the result score as a protrusion index (PI) [Ponomarenko et al., 2008]. The specifications for conformational epitope prediction were fixed at 0.8 for minimum score and 7 Angstrom $(\AA)$ for maximum distance.

\section{Assessment of Physicochemical properties}

ExPASy ProtParam tools (https://web.expasy.org/protparam/) was used for the assessment of various physiochemical properties of SARS-CoV-2 proteins and the potential vaccine candidates. Properties like amino acid composition, molecular weight, extinction coefficient, isoelectric point ( $\mathrm{pI}$ ), instability index, aliphatic index, stability (in bacterial, yeast, and mammalian system) grand average hydropathicity (GRAVY) value was identified by ExPASy ProtParam [Gasteiger et al., 2005].

\section{Results}

\section{Retrieval of SARS-CoV-2 proteins and determination of antigenicity of structural proteins}

A total of ten protein sequences of SARS-CoV-2 (orflab polyprotein, surface glycoprotein or spike protein, orf3a protein, envelope protein, membrane glycoprotein, orf6, orf7a, orf8 proteins and nucleocapsid phosphoprotein) was retrieved from viPR database, out of which six confirmed structural protein (surface glycoprotein, orf3a protein, envelope protein, membrane glycoprotein, orf6 protein, nucleocapsid phosphoprotein) was selected for the epitope-based vaccine designing. Antigenicity analysis of all the six structural proteins was performed by Vaxijen server. The Vaxijen score of all these proteins were above threshold level, $\geq 0.4$ (Table-S1), thus all six selected proteins were antigenic in nature. Highest Vaxijen score was observed for Orf 6 protein (0.6131) and minimum was found in case of surface glycoprotein (0.4646).

\section{T-Cell Epitope Prediction}

The web based server NetCTL 1.2 was used for the identification of CD8 ${ }^{+}$T-cell epitopes and the combined score was considered for the selection of epitopes. From the protein sequences of $\mathrm{S}, \mathrm{ORF} 3 \mathrm{a}, \mathrm{E}, \mathrm{M}, \mathrm{ORF} 6$, and N proteins, the server predicted a total of 83, 33, 10, 31, 4 and 26 epitopes, respectively (Table-S2).

Peer] reviewing PDF | (2020:04:47510:1:1:NEW 24 Jun 2020) 
358

359

360

361

362

363

364

365

366

367

368

369

370

371

372

373

374

375

376

377

378

379

380

381

382

383

384

385

386

387

388

389

390

391

392

393

394

395

396

397

\section{Analysis of antigenicity and immunogenicity:}

All the 187 identified T-cell epitopes were then evaluated for antigenicity by the VaxiJen server and then for immunogenicity by IEDB server. However, only 97 epitopes from all the six structural proteins were regarded as antigenic based on VaxiJen scores. Similarly, 106 epitopes had immunogenicity values more than the threshold value when analyzed by IEDB tool (TableS2). Altogether 82 epitopes were selected on the basis of positive scores for both antigenicity and immunogenicity (Table-S3). The HLA-binding affinity of the epitopes is described by the IC50 $\mathrm{nM}$ unit. Higher binding affinity of the epitopes with the MHC class I molecule is reflected by the lower IC50 value. Therefore, IC50 values less than 250nM (IC50<250) were fixed for securing higher binding affinity. The IC50 values of the epitopes were determined by the IEDB tool (Table-S3). These selected epitopes were then subjected to evaluation of conservancies. We eventually selected 38 epitopes from all the six structural proteins that had a conservancy scores greater than $65 \%$ (Table-1).

\section{Evaluation of allergenicity and toxicity}

The allergenicity determination of the potential epitopes is a critical step in vaccine design. Therefore, Allergen FP 1.0 server and AllerTOP v. 2.0 were used for identifying the allergens in the $\mathrm{T}$ cell epitopes. About one third of the epitopes were non-allergenic, while remaining two third were allergic, when the tool, Allergen FP 1.0 was used for evaluation. However, when AllerTOP v. 2.0 was used for the identification of allergenicity, only ten epitopes were found to be allergenic in nature. The server recognized thirteen epitopes from the proteins as non-allergen (Table-1). All the predicted epitopes of MHC-1 from structural proteins of SARS-CoV-2 were indicated as non-toxic, when ToxinPred was used for the toxicity assessment (Table-1).

\section{Selection of potential MHC-I epitopes for vaccine design:}

The potential $38 \mathrm{CD}^{+} \mathrm{T}$ cell epitopes from six structural proteins were finally evaluated for all the above parameters simultaneously for determination of most suitable vaccine candidates. Among the S protein epitopes, "YQPYRVVVL" exhibited high binding affinity for seven MHCI molecules viz; (i) HLA-C*12:03 (37.77) (ii) HLA-A*02:06 (68.16), (iii) HLA-B*39:01 (75.92), (iv) HLA-B*15:02 (92.94), (v) HLA-B*15:01 (181.97), (vi) HLA-C*14:02 (198.89), (vii) HLA-C*03:03 (199.8) (Table-S3). It had the VaxiJen score of 0.5964 and the immunogenicity score of 0.14090 , which were well above the respective threshold values. The conservancy score of the epitope was $100.00 \%$ and both the allergenicity prediction tools identified this epitope as non allergenic. Furthermore, it was nontoxic as determined by the toxicity analysis tool used in this study. Similarly, three more epitopes from spike protein viz; 'QLTPTWRVY', 'PYRVVVLSF' and 'GVYFASTEK' exhibited desired values for the above parameters (highlighted with yellow color in Table-1).

Next, the epitopes from ORF3a was selected on the basis of outcomes of the parameters evaluated in the study. The epitope 'HVTFFIYNK' also showed binding capabilities with seven MHC class I alleles. The VaxiJen score of 0.9862 and immunogenicity score of 0.36278 was found for the epitope 'HVTFFIYNK'. Further, with the conservancy value of $66.67 \%$ and being non-allergenic and nontoxic this epitope can be regarded as best vaccine candidate from ORF3a 
398

399

400

401

402

403

404

405

406

407

408

409

410

411

412

413

414

415

416

417

418

419

420

421

422

423

424

425

426

427

428

429

430

431

432

433

434

435

436

protein. Likewise one more epitope 'LKKRWQLAL' was marked as potential vaccine candidates based on their scores gathered during the analysis by the computational tools (Table-1 \& Table-S3).

In contrast to epitopes from spike and ORF3a proteins, although E protein epitope "LLFLAFVVF" exhibited binding affinity with seven MHC I alleles and high antigenicity, immunogenicity, it could not pass the allergenicity evaluation. Thus, no epitope from envelope protein could be regarded as potential vaccine candidates.

Among epitopes from M protein, "LTWICLLQF" had high antigenicity score of 1.1393 and immunogenicity score of 0.06584. 'LTWICLLQF' exhibited binding to (i) HLA-C*14:02 (129.6), (ii) HLA-B*58:01, (141.02), (iii) HLA-C*12:03 (166.42), (iv) HLA-A*32:01 (245.43) molecules and had a conservancy score of $77.78 \%$. Furthermore, the epitope was non-allergenic and had no toxicity, thus can be regarded as one of the best vaccine candidates from M protein. One more epitope "RFLYIIKLI" had better scores in the computational analysis performed for the evaluation of vaccine potential (Table-1 \& Table-S3).

Similar to envelope protein, ORF6 epitope also did not show any promising vaccine candidate that could fulfill all the criteria evaluated in our study (Table-1).

Last of the selected structural protein, nucleocapsid protein showed three promising epitopes, when evaluated by the computational tools. One of three epitopes; "KTFPPTEPK" displayed significant binding affinities with nine MHC-1 molecules. It had VaxiJen score of 0.7571 and immunogenicity score of 0.13060 . The conservancy was $100.00 \%$ for this epitope and was categorized as non-allergen and non-toxic by the computational tools. Two other epitopes 'SPRWYFYYL' and 'TWLTYTGAI' also fulfilled all the criteria analyzed in the study for the determination of vaccine potential (Table-1 \& Table S3).

\section{Analysis of Population Coverage}

The distribution of MHC HLA alleles varies across various geographic territories and ethnic classes throughout the world. Consequently, consideration of population coverage is essential prerequisite for designing an effective vaccine. IEDB population coverage tool was thus used to predict the population coverage of all the shortlisted T-cell epitopes (Table-1) and their respective MHC-I-binding alleles. Remarkable population coverage was identified for the epitopes in different geographic regions of the world (Figure-S1 and Table-S4).

\section{Prediction of MHC II epitopes:}

The MHC II epitopes of 15-mer length were derived from the sequences of $\mathrm{CD}^{+} \mathrm{T}$ cell epitopes and were evaluated on the basis of IC50 scores. The promising CD8 ${ }^{+} \mathrm{T}$ cell epitopes "YQPYRVVVL" and "QLTPTWRVY" were evaluated first. The analysis revealed that the epitope sequence "YQPYRVVVL" was present as the core sequence in more than fifty predicted MHC II epitopes, whereas the epitope "QLTPTWRVY" was found as the core sequence of a single CD4+ T-cell epitope (Table-S5). The MHC II epitopes containing the core peptide "LKKRWQLAL" from ORF3a was found to be present as the core sequence in 44 predicted MHC II epitopes (Table-S5). 
437 More than forty CD4 ${ }^{+} \mathrm{T}$ cell epitopes having the core sequence "LTWICLLQF" derived from M 438 protein had a range of binding affinities with IC50 values between 61-2801 nM (Table-S5).

439 As the computational analysis of ORF6 and envelope protein did not result in any potential CD8 ${ }^{+}$ 440 T cell epitope, the MHC II epitopes derived from these proteins were not considered further.

441 Lastly, the search for MHC II binding epitopes using the core peptide "KTFPPTEPK" could not

442 result in the potential epitopes in the acceptable range of the IC50 value $1-3000 \mathrm{nM}$.

443 Docking Simulation Analysis:

$444 \mathrm{The}_{\mathrm{CD}}{ }^{+} \mathrm{T}$ cell epitopes which were considered to be potential vaccine candidates based on 445 appropriate values obtained during the analysis by the computational tools were used in the 446 docking simulation studies. The binding models of epitopes and their respective HLA molecules 447 (both class I and class II) were generated by taking advantage ofHADDOCK 2.4. The tool 448 generated clusters and the numbering of cluster reflected the size of the cluster. The various 449 components of the HADDOCK results like HADDOCK score, Cluster size, Root mean square 450 deviation (RMSD) from the overall lowest-energy structure, Van der Waals energy, Electrostatic 451 energy, Desolvation energy, Restraints violation energy, Buried Surface Area, and Z-Score were 452 reported for each cluster on the results web page. Irrespective of the number of cluster, the top cluster is considered as most reliable according to HADDOCK. Therefore, the first cluster from the result displayed by HADDOCK server was selected for visualization of structures. The more

455

456

457

458

459

460

461

462

463

464

465

466

467

468

469

470

471

472

473

474

475

476 negative results of HADDOCK score and $\mathrm{Z}$ score signifies better structures and interaction. At the first instance two promising MHC I epitopes viz; "PYRVVVLSF", "QLTPTWRVY" from surface glycoprotein was used for the docking with HLA-C*07:02. The Haddock score of the first cluster was $-30.4+/-7.5$ and the $\mathrm{Z}$ score was -1.2 indicating the proper docking solution for HLA-C*07:02 and epitope PYRVVVLSF (Table-2). Similarly the second epitope

"QLTPTWRVY" from S protein also had negative values for both the HADDOCK score and Z score indicating the cluster as a good docking solution. In the next HADDOCK analysis epitope "HVTFFIYNK" from ORF3a was used along with the HLA-A*30:01. The best cluster had the HADDOCK score of $-65.5+/-7.7$ and the $\mathrm{Z}$ score of -1.8 , suggesting proper docking results. Another round of docking studies was performed with the MHC I peptide "LTWICLLQF" obtained from the membrane protein and the structure of HLA-B*58:01 molecule derived from PDB. HADDOCK and Z score of the best cluster of this pair were also promising and could be used for the structure visualization. Finally epitope "SPRWYFYYL" from nucleocapsid protein was selected for docking with the HLA-B*08:01 molecule, which resulted in the Haddock score of -29.3 +/- 3.2 and the $\mathrm{Z}$ score of -2.1 (Table-2). In the next step model structures of all the above best clusters obtained in the HADDOCK results were downloaded. Then 3D model of the clusters were visualized by PYMOL and Discovery Studio was utilized for getting the 2D interaction map (Figure-2). All the 3D and 2D interaction map indicated binding in the antigen binding groove thus providing proper docking solutions by HADDOCK. Altogether three promising MHC II epitopes were used for HADDOCK docking analysis. First docking analysis was performed using HLA-DRB1*01:01 structure obtained from PDB and the structure of MHC class II epitope "TNGVGYQPYRVVVLS" (from S protein) predicted using 
477 PEPFOLD tool. The HADDOCK protocol produced the best cluster with the HADDOCK score 478 of $-38.1+/-9.9$ and the $Z$ score of -2.2 , which indicated optimum solution of docking. The 479 second docking analysis between the MHC-II allele (HLA-DRB1*01:01) and epitope 480 "ITLKKRWQLALSKGV" from ORF3a protein also resulted in desired negative values of 481 HADDOCK and $Z$ scores The last HADDOCK docking examination was performed with the 482 MHC II allele (HLA-DRB1*04:01) and the epitope "LFLTWICLLQFAYAN" from membrane

483

484

485

486

487

488

489

490

491

492

493

494

495

496

497

498

499

500

501

502

503

504

505

506

507

508

509

510

511

512

513

514

515

516 glycoprotein of SARS-CoV-2, which revealed a HADDOCK score of $-78.4+/-10.7$ and the $\mathrm{Z}$ score of -1.6 (Table-2). Similar to MHC I, the model structures of all the above three best clusters obtained in the HADDOCK results were downloaded from the HADDOCK result page. 3D models of the clusters were visualized by PYMOL and Discovery Studio was implied for getting the 2D interaction maps of all three docking solutions (Figure-3). All three 3D and 2D interaction images exhibited proper MHC II allele and epitope binding suggesting appropriate docking solutions by HADDOCK (Fig.-3).

\section{Re-docking and Validation of docking methods:}

For the validation of docking methodologies crystal structures of seven HLA alleles and the corresponding epitopes as described in method section were selected and all the procedures described for HADDOCK 2.4 were followed for re-docking. The HADDOCK scores were in the range of $-29.6+/-7.8$ to $-65.0+/-2.1$ fo the MHC I epitopes while it was $-92.1+/-5.8$ and -96.7 $+/-5.6$ for the two MHC II epitopes. The $\mathrm{Z}$ scores were also in the range of -1.0 to -2.3 for MHC I structures while it was 0.0 and -1.5 for MHC II alleles (Table-S6). Then 3D and 2D structures of the best clusters were visualized using PYMOL and Discovery studio/ LigPLOT+. The results indicated proper docking solutions provided by HADDOCK and the structures were similar as available in the PDB (Figure-S2). The desired findings with the known epitopes and HLA alleles suggested the appropriate and acceptable approach of HADDOCK protocol implied in the HADDOCK 2.4 .

\section{Analysis of Linear and Conformational B-Cell Epitopes}

B-cell epitope is a segment of an antigen recognized in a humoral immune response by either a specific B-cell receptor or by the evoked antibody [Peters et al., 2005; Sun et al., 2013]. The Bcell epitopes are categorized into two distinct groups as (i) continuous or linear and (ii) discontinuous or conformational B-cell epitopes. One of the significant steps of epitope-based vaccine design is the identification of B-cell epitopes from the antigenic proteins of pathogens. Consequently, the web server based computational tools, BepiPred-2.0 and LBtope were used to find out B-cell vaccine candidates in the different proteins of SARS-CoV-2.

The BepiPred-2.0 generated fair number of linear B-cell epitopes from the S protein of SARS$\mathrm{CoV}-2$. Among these linear epitopes eleven were non-antigenic as predicted by the VaxiJen v2.0 server and had conservancy level between 56.25 to $97.50 \%$ (Table-S7). Accordingly, these epitopes could not be considered as prospective vaccine candidates. Conversely, six epitopes; (i) GQSKRVDFC, (ii) VEAEVQI, (iii) SCCKFDEDDSEPVLKGVKL,(iv) GDEVRQIAPGQTGKIADYNYK, (v) YQTSNFRVQP and (vi) NSASFSTFKCYGVSPTKLND LCFTNV can be regarded as vaccine candidates due to their antigenicity and high conservancy 
517 scores (Table-3). Nevertheless, the epitope 'SCCKFDEDDSEPVLKGVKL' being toxic in 518 nature could not be considered as the potential vaccine candidate. Based on the results of 519 allergenicity (AllerTOP 2.0 and AllergenFP v. 1.0) and toxicity, epitope

520 'NSASFSTFKCYGVSPTKLNDLCFTNV' could be considered as best potential linear B-cell 521 epitope for vaccine design (highlighted in Table-3). Over twenty linear B-cell epitopes were 522 recognized from the S protein using LBtope (Table-S7). Altogether seven epitopes were non523 antigenic and cannot be considered as good vaccine candidates. The epitope

524 'AGAAAYYVGYLQPRT' had high antigenicity and high conservancy scores and were not 525 classified as allergen by the tools, hence can be considered as potential vaccine candidate.

526 Compared to the spike protein, only five linear B-cell epitopes from ORF3a protein were 527 identified by BepiPred-2.0 (Table-S7). Out of these epitopes, three were non-antigenic as

528

529

530

531

532

533

534

535

536

537

538

539

540

541

542

543

544

545

546

547

548

549

550

551

552

553

554

555

556

discerned by the VaxiJen v2.0 server and their conservancy scores varied between 57.69 to 74.29 $\%$. On the other hand, two epitopes; (i) 'QGEIKDATPSDF' and (ii) 'KIITLKKRWQL' can be considered as vaccine candidates due to their antigenicity and conservancy score (Table-3). After due consideration of all the factors like allergenicity (AllerTOP 2.0 and AllergenFP v. 1.0) and toxicity, none of the epitope predicted by BepiPred- 2.0 could be safely recommended as potential linear B-cell epitopes. Another tool for linear epitope discovery, LBtope, led to the identification of only three linear B-cell epitopes from the ORF3a protein. Although, two epitopes; 'EIKDATPSDF and WKCRSKNPLL had fair values for antigenicity and high conservancy score, but owing to its toxicity, it cannot be projected as potential vaccine candidates. The evaluation of antigenicity, conservancy, toxicity, and allergenicity of B-cell epitopes suggested that none of the linear B-cell epitopes from ORF3a could be considered as candidates for peptide-based vaccine design.

When the E protein was investigated using BepiPred-2.0 server, only one epitope; 'YVYSRVKNLNSSRVP' was identified as linear B-cell epitope (Table-S7). It showed good antigenicity with non-allergenic and non-toxic property and a conservancy score of $80.00 \%$. Similarly, LBtope also showed only one epitope, YVYSRVKNLNSSRVPDLL that too was antigenic, non allergenic and non toxic with conservancy score of $72.22 \%$. Consequently, YVYSRVKNLNSSRVP can be regarded as most potential B-cell epitope candidate from E protein for peptide-based vaccine (Table-3).

The search for potential linear B-cell epitopes from M and ORF6 protein by BepiPred-2.0 and LBtope could not be successful as none of the predicted epitope could satisfy all the criteria evaluated in the present study.

The search of linear B-cell epitopes in N protein by BepiPred-2.0 resulted in identification of eight epitopes (Table-S7). Among the predicted epitopes four were reported as non-antigenic by the VaxiJen v2.0 server. Out of the remaining four epitope only two epitopes viz; "HGKEDLKFPRGQGVPINTNSSPDDQIGYYRRATRRIRGGDGKMKDLS", and "LNQLESKMSGKGQQQ QGQTVTKKSAAEASKKPRQKRTATK" could be considered as the potential linear B-cell epitopes for vaccine development. On the other hand only 4 linear Bcell epitopes were predicted by LBtope (Table-S7). The analysis of antigenicity, conservancy,

Peer] reviewing PDF | (2020:04:47510:1:1:NEW 24 Jun 2020) 
557 toxicity, and allergenicity of B-cell epitopes identified by LBtope revealed that epitopes,

558

559

560

561

562

563

564

565

566

567

568

569

570

571

572

573

574

575

576

577

578

579

580

581

582

583

584

585

586

587

588

589

590

591

592

593

594

595

596

DNGPQNQRNAPRITFGGP, GERSGARSKQRRPQGL could be regarded as the most potential B-cell linear epitope (Table-3).

For identifying conformational B-cell epitopes, the ElliPro tool of IEDB was utilized in this study, and a total of eleven discontinuous peptides were identified when the structural proteins of SARS-CoV-2 were used as targets. The ElliPro tool evaluates results based on the protrusion index (PI) score, and the PI score above 0.8 are considered significant. The PI value of the 11 predicted epitopes ranged from 0.809 to 0.911 and the epitopes with higher scores indicated greater solvent accessibility. Conformational epitopes and their associated parameters and scores revealed that epitopes with highest number of residues (110) were present in conformational epitopes from $\mathrm{S}$ protein and the minimum number of residues (03) was predicted from M protein (Table-S8). The three dimensional structure and location of the conformational epitopes were displayed by ElliPro (Figure-4).

\section{Analysis of Physicochemical properties}

Physicochemical properties of the SARS-CoV-2 structural proteins are described in Table-S9. The values revealed that the S, ORF3a and ORF6 proteins were naturally acidic whereas the E, $\mathrm{M}, \mathrm{N}$ protein were naturally basic. All the six structural proteins from SARS-CoV-2 used in the study had estimated half-life of 30 hours in mammalian reticulocytes under in vitro conditions, whereas in yeast the estimated half life was more than 20 hours. The least survival time of more than 10 hours was estimated in Escherichia coli. Unlike the proteins, proposed MHC I epitopes had different half life. An estimated half life of less than an hour in mammalian reticulocytes was associated with QLTPTWRVY epitope derived from S protein, whereas maximum half life of thirty hours was estimated for GVYFASTEK. On the other hand least estimated half life in yeast system was predicted for RFLYIIKLI and however maximum estimated half life of more than 20 hours was found in case of four epitopes (Table-S9). Lastly in the most commonly used protein expression system i.e., E. coli five epitopes had a life of more than ten hours.

Similarly, out of the four potential MHC II epitopes two had the maximum estimated half life of 20 hours in mammalian reticulocytes, while, three epitopes had an estimated half life of more than $10 \mathrm{~h}$ in E. coli. In contrast, no MHC II epitope had an estimated half life of more than 30 minutes in yeast system (Table-S9). These estimated half lives of MHC I and MHC II peptide epitopes suggested that most of the promising vaccine candidates could safely be produced in one or the other protein expression systems mentioned above.

\section{Discussion}

The advancing pandemic of corona virus disease 2019 (COVID-19) has resulted in death of more than 445000 human population globally [COVID-2019-situation report-150]. The disease is generated by severe acute respiratory syndrome corona virus 2 (SARS-CoV-2) [Corona virus disease 2019-WHO]. Keeping the SARS-CoV-2 (RNA-virus) mutability in mind [Twiddy et al., 2003; Manzin et al., 1998], a comprehensive vaccine needs to be designed to overcome the adverse effects of this viral infection. However, an efficacious vaccine development and mass production are expensive and can take several years to be completed. Therefore, an attempt was

Peer] reviewing PDF | (2020:04:47510:1:1:NEW 24 Jun 2020) 
597 made to design a peptide-based vaccine using the immuno-informatics approaches to minimize 598 the time required for searching a potent vaccine candidate for SARS-CoV-2 At present, distinct 599 Bioinformatics approaches are available for the design and development of successful and safe 600 new-generation vaccines [María et al., 2017; Seib et al., 2012]. The advancement in 601 computational immunology and newer immuno-informatics tools have created a broader way in 602 developing the vaccine or vaccine candidates by the adequate understanding of the human 603 immune response against a pathogen within a short period of time [de Groot and Rappuoli, 604 2004; Korbe et al., 2006; Purcell et al. 2007]. The scheme of an epitope-based vaccine against 605 rhinovirus, [Lapelosa et al., 2009] dengue virus, [Chakraborty et al., 2010] chikungunya virus, 606 [Islam et al., 2012] Saint Louis encephalitis virus, [Hasan et al., 2013] etc. has already been 607 proposed.

608 In the present study, we first attempted to identify the potential vaccine candidates based on the $609 \mathrm{~T}$ cell peptide epitope. In contrast to earlier vaccines, which are predominantly based on B cell 610 immunity, vaccine based on $\mathrm{T}$ cell epitope has also been recommended as the host can induce a 611 strong immune response by $\mathrm{CD} 8^{+} \mathrm{T}$ cell against the infected cell [Van Regenmortel, 2001]. Due 612 to antigenic drift, any foreign particle can escape the antibody memory response mounted by B 613 cells; however, the immune response generated by $\mathrm{T}$ cells usually provides long-lasting 614 immunity. There are various specifications that need to be fulfilled by a peptide vaccine 615 candidate. The potential epitopes proposed in our study satisfied all the criteria evaluated using 616 computational tools.

617 The T-cell epitope was identified based on high threshold values (1.25) obtained in the output of 618 NetCTL 1.2 tool. Primarily, more than one hundred fifty epitopes from six structural proteins 619 were identified by selecting twelve super types of MHC-1 alleles. The antigenicity, 620 immunogenicity and conservancy of the epitopes are considered as important determinants.

621 Therefore, by maintaining critical thresholds of the antigenicity, immunogenicity and 622 conservancy of the epitopes, we picked thirty eight epitopes from structural proteins of SARS-

$623 \mathrm{CoV}-2$ (Table-1). These selected T-cell epitopes had a higher conservancy between 65.0 to $624100.0 \%$, which further support the feasibility of these predicted epitopes and indicate them as a 625 potential vaccine candidate.

626 Most of the present day vaccines activate the immune system into allergic state [McKeever et al., 627 2004] by inducing type $2 \mathrm{~T}$ helper T (Th2) cells and immunoglobulin E (IgE). Consequently, 628 allergenic property is one of the major hurdles in vaccine development. Hence, all the selected T629 cell epitopes were screened for allergenicity by two computational tools; AllerTOP v.2.0 and 630 AllergenFP 1.0. Altogether only eleven epitopes were classified by both the tools as non631 allergens. Those eleven epitopes with all the characteristics of good vaccine candidates may be 632 considered most important epitope in comparison with the other epitopes.

633 Another important factor in the selection of a potential vaccine is population coverage. The 634 human leukocyte antigen alleles are remarkably polymorphic in diverse ethnic populations. 635 Consequently, allele specificity of T-cell epitopes is considered as the initial criterion for the 636 induction of proper immune responses in numerous ethnic human populations [Stern and Wiley, 
637 1994]. For all the eleven promising T cell vaccine candidates, the cumulative percentage of 638 population coverage was measured. Overall the recommended epitopes from surface 639 glycoprotein showed world population coverage of $80.37 \%$ followed by nucleocapsid

640 phosphoprotein and ORF3a epitopes showing $68.10 \%$ and $54.43 \%$ of world population coverage, 641 respectively (Table-S4). The SARS-CoV-2 outbreak has resulted pandemic in which cases have

642 been reported in almost all the countries of world [WHO situation report-150], so a vaccine 643 candidate which can protect the majority of world's population is required.

644 However, the epitopes from membrane protein could cover only $31.04 \%$ population of World. 645 Notably, the epitopes from the surface protein had population coverage of $89.08 \%$ for China, 646 where the virus originated [Zhou et al., 2020] and 88.99\% for Southeast Asia. In the list of badly hit countries, majority is from Europe [WHO situation report-150] and the epitope from $\mathrm{S}$

648 protein had coverage of $80.69 \%$ of Europe's population. The population coverage of $77.72 \%$ was obtained for USA where the highest number of cases has been reported [WHO situation report-

650 150]. The nucleoprotein epitopes covered $76.28 \%$ of Europe population followed by $69.53 \%$ and $63.26 \%$ of Italy and United States populations; respectively. Next, the ORF3a epitopes had $64.57 \%$ coverage of China's population followed by $63.85 \%$, and $57.98 \%$ of Hong Kong and

653

654

655

656

657

658

659

660

661

662

663

664

665

666

667

668

669

670

671

672

673

674

675

676
Europe's population, respectively. Taken together all the suggested epitopes having higher population coverage may be considered as strong vaccine candidates.

The proper binding of the T cell epitope to the MHC I antigen binding cleft is essential for the induction of desired immune response [Stern and Wiley, 1994]. The legitimate binding should result in a negative HADDOCK and $\mathrm{Z}$ scores. Thus the 3D structure of the proposed vaccine candidate was designed using PEP-FOLD and the crystal structure of the selected MHC allele was obtained from Protein Data Bank (PDB). Thereafter, removal of water and retrieval of chain wise structure of MHC alleles were performed using PyMol. In the next step molecular docking simulation was executed with selected chain of the MHC as protein molecule and the proposed vaccine candidate as ligand using HADDOCK 2.4. The HADDOCK and $\mathrm{Z}$ scores, the two most significant parameters in the results of HADDOCK indicated the predicted epitopes to be reasonable. The 3D and 2D interaction maps were derived using the HADDOCK best cluster model generated in result page by applying appropriate bio-informatics resources like PYMOL and Discovery studio. These structures exhibited appropriate binding of predicted epitopes in MHC I peptide binding cleft suggesting the pertinent selection of bio-informatics approach for epitope identifications. The re-docking and validation of docking method was carried out by using the seven crystal structures of MHC I and MHC II alleles and their corresponding peptide epitope obtained from PDB. The structures of both HLA allele and corresponding peptides were obtained using PyMol and re-docking was performed using HADDOCK 2.4. The docking procedures were same as that for the SARS-CoV-2 predicted epitopes. HADDOCK and Z scores were in the acceptable range (negative values) and the $3 \mathrm{D}$ and $2 \mathrm{D}$ interaction results were similar to the corresponding PDB structures. Furthermore the results of HADDOCK re-docking were similar to those achieved by dockings performed using the predicted SARS-CoV-2 MHC I and MHC II epitopes, which reflected valid docking methodologies adopted in the present study. The 
677 physicochemical properties of proposed epitopes indicated that these can be produced in any 678 three of the systems used for the expression of peptides, viz, mammalian cells, Yeast cell or $E$. 679 coli (Table-S9)

680 Most of the current day vaccines are based on the B cell epitopes [Sarkander et al., 2016].

681 BepiPred-2.0 might be viewed as the prime and most up-to-date B-cell epitope prediction

682 computational tool as it exhibits notably good performance on both epitope data obtained from a

683 vast number of linear epitopes taken from the IEDB database and on structural data of epitope

684 derived from crystallography studies. LBtope is other robust tool for linear B-cell epitope

685 prediction. It has been generated based on the experimentally proven non B-cell epitopes derived

686 from the IEDB database. Antigenicity, allergenicity, toxicity and conservancy of the predicted B

687 cell linear epitopes are prime determinants for identifying potential vaccine candidates.

688 Therefore, all the four criteria were evaluated using different standard bioinformatics tools and

689 potential epitopes were selected on the basis of high threshold values as fixed for $\mathrm{T}$ cell epitopes.

690 Thus, on the basis of above criteria and conservancy altogether seven B cell epitopes from

691 structural proteins were proposed as potential B cell vaccine candidates. The majority of the B-

692 cell epitopes are discontinuous or conformational epitopes, and the quantum of this epitope is

693 more than 90\% [Van Regenmortel 2001]. Therefore, discontinuous B-cell epitopes were

694 identified using ElliPro, a strong tool for the identification of conformational B cell epitopes. The

695 tool identified 4 epitopes from surface glycoprotein followed by 2 epitopes each from the orf3a

696 protein, membrane protein and nucleocapsid phosphoprotein. The extensive range of these

697 conformational epitopes drawn on different proteins of SARS-CoV-2 indicated their potential as

698 conformational B cell vaccine candidates.

699 An earlier study has reported a single epitope from spike protein having the conservancy of

700 about $64 \%$ [Oany et al., 2014]. Here we have reported several epitopes as potential vaccine

701 candidates from five structural proteins of SARS-CoV-2. As all the vaccine candidates need to

702 be verified in clinical trials, the normal path of vaccine development, we propose the identified

703 potential vaccine candidates should be pursued in clinical trials.

704 Conclusions

705 In view of the present COVID-19 pandemic, for development of vaccine efficiently and within

706 minimal time, vaccine candidates need to be identified at the early. Based on advanced

707 computational approaches, we have altogether identified eleven potential T-cell epitopes, seven

708 B cell linear epitopes and ten B cell conformational epitopes from the six structural proteins of

709 SARS-CoV-2. Taken together these numerous potential vaccine candidates may provide

710 important timely avenues for effective vaccine development against SARS-CoV-2. The future

711 efforts may focus on the clinical trials of the multi-epitope vaccine candidates based on the

712 present study.

713

714 Acknowledgements

715 The authors acknowledge the infra-structure developed under DBT-BUILDER Project by DBT.

716 


\section{References:}

718

719 Adhikari UK, Tayebi M, Rahman MM. 2018. Immunoinformatics approach for epitope-based 720 peptide vaccine design and active site prediction against polyprotein of emerging oropouche 721 virus. Journal of immunology research. 2018: 6718083. DOI: $10.1155 / 2018 / 6718083$

722 Andersen KG, Rambaut A, Lipkin WI, Holmes EC, Garry RF. 2020. The proximal origin of

723 SARS-CoV-2. Nature medicine 26(4):450-2. DOI: 10.1038/s41591-020-0820-9

724 Bui HH, Sidney J, Li W, Fusseder N, Sette A. 2007. Development of an epitope conservancy

725 analysis tool to facilitate the design of epitope-based diagnostics and vaccines. BMC

726 Bioinformatics 8:361. DOI:10.1186/1471-2105-8-361

727 Calis JJ, Maybeno M, Greenbaum JA, Weiskopf D, De Silva AD, Sette A, Keşmir C, Peters B.

728 2013. Properties of MHC class I presented peptides that enhance immunogenicity. PLoS

729 Computational Biology 9(10):e1003266. DOI: 10.1371/journal.pcbi.1003266, PMID: 24204222;

730 PMCID: PMC3808449.

731 Chakraborty S, Chakravorty R, Ahmed M, Rahman A, Waise TM, Hassan F, Rahman

732 M, Shamsuzzaman S. 2010. A Computational Approach for Identification of Epitopes in Dengue

733 Virus Envelope Protein: A Step Towards Designing a Universal Dengue Vaccine Targeting

734 Endemic Regions. In Silico Biology 10 (5-6):235 - 246. DOI: 10.3233/ISB-2010-0435,

735 PMID:22430357

736 Coronavirus disease (COVID-2019) situation reports: Situation Report -150

737 (https://www.who.int/docs/default-source/coronaviruse/situation-reports/20200618-covid-19-

738 sitrep-150.pdf?sfvrsn=aa9fe9cf 2)

739 Coronavirus disease 2019 (https://www.who.int/emergencies/diseases/novel-coronavirus-2019).

740 World Health Organization.

741 Dassault Systèmes BIOVIA, Discovery Studio Visualizer, Release 2020, San Diego: Dassault

742 Systèmes, 2019.

743 De Groot AS, Rappuoli R. 2004. Genome-derived vaccines. Expert Review of Vaccines 3(1):59-

744 76. DOI:10.1586/14760584.3.1.59, PMID:14761244

745 de Wilde AH, Snijder EJ, Kikkert M, van Hemert MJ. 2018. Host Factors in Coronavirus

746 Replication. Current Topics in Microbiology Immunology 419:1-42. DOI:10.1007/82_2017_25,

747 PMID:28643204 
748 de Wit E, van Doremalen N, Falzarano D, Munster VJ. 2016. SARS and MERS: recent insights

749 into emerging coronaviruses. Nature Review Microbiology 14(8):523-34. DOI:

750 10.1038/nrmicro.2016.8, PMID: 27344959; PMCID: PMC7097822.

751 Dhanda SK, Karosiene E, Edwards L, Grifoni A, Paul S, Andreatta M, Weiskopf D, Sidney J,

752 Nielsen M, Peters B, Sette A. 2018. Predicting HLA CD4 immunogenicity in human

753 populations. Frontiers in immunology. 9:1369. https://doi.org/10.3389/fimmu.2018.01369

754 Dimitrov I, Bangov I, Flower DR, Doytchinova IA. 2014. AllerTOP v.2 - a server for in silico

755 prediction of allergens. Journal of Molecular Modeling 20(6):2278, (a). DOI:10.1007/s00894-

$756 \quad 014-2278-5$

757 Dimitrov I, Naneva L, Doytchinova I, Bangov I. 2014a. AllergenFP: Allergenicity Prediction

758 by Descriptor Fingerprints. Bioinformatics 30(6):846-851. DOI:10.1093/bioinformatics/btt619,

759 PMID:24167156

760 Dong N, Yang X, Ye L, Chen K, Chan EW-C, Yang M, Chen S. 2020. Genomic and protein

761 structure modelling analysis depicts the origin and infectivity of COVID-19, a new corona virus

762 which caused a pneumonia outbreak in Wuhan, China. Microbiology.

763 DOI:10.1101/2020.01.20.913368

764 Doytchinova IA., Flower DR. 2007. VaxiJen: a server for prediction of protective antigens, 765 tumour antigens and subunit vaccines. BMC Bioinformatics 8(4). DOI:10.1186/1471-2105-8-4

766 Gasteiger E, Hoogland C, Gattiker A, Duvaud S, Wilkins MR, Appel RD, and Bairoch A. 2005.

767 Protein identification and analysis tools on the ExPASy server. The Proteomics Protocols

768 Handbook, J. M. Walker: 571-607, Humana Press, Totowa, NJ, USA. DOI: 10.1385/1-59259-

769 890-0:571

770 Gras S, Kedzierski L, Valkenburg SA, Laurie K, Liu YC, Denholm JT, Richards MJ,

771 Rimmelzwaan GF, Kelso A, Doherty PC, Turner SJ, Rossjohn J, Kedzierska K. 2010. Cross-

772 reactive CD8+ T-cell immunity between the pandemic H1N1-2009 and H1N1-1918 influenza A

773 viruses. Proceedings of the National Academy of Sciences of the United States of America

774 107(28):12599-12604. DOI: 10.1073/pnas.1007270107, PMID: 20616031; PMCID:

775 PMC2906563.

776 Gupta S, Kapoor P, Chaudhary K, Gautam A, Kumar R; Open Source Drug Discovery

777 Consortium, Raghava GP. 2013. In silico approach for predicting toxicity of peptides and 
778 proteins. PLoS One 8(9):e73957. DOI: 10.1371/journal.pone.0073957, PMID: 24058508;

779 PMCID: PMC3772798.

780

781

782

783

784

785

786

787

788

789

790

791

792

793

794

795

796

797

798

799

800

801

802

803

804

805

806

807

\section{HADDOCK 2.4 basic protein-protein docking tutorial}

https://www.bonvinlab.org/education/HADDOCK24/HADDOCK24-protein-proteinbasic/\#analysing-the-results

Hasan MA, Hossain M, Alam MJ. 2013. A computational assay to design an epitope-based Peptide vaccine against saint louis encephalitis virus. Bioinformatics and Biology Insights 7:347355. DOI: 10.4137/BBI.S13402, PMID: 24324329; PMCID: PMC3855041.

Hofmann H, Pyrc K, van der Hoek L, Geier M, Berkhout B, Pöhlmann S. 2005. Human coronavirus NL63 employs the severe acute respiratory syndrome coronavirus receptor for cellular entry. Proceedings of the National Academy of Sciences 102(22):7988-7993.

Huang C, Wang Y, Li X, Ren L, Zhao J, Hu Y, Zhang L, Fan G, Xu J, Gu X, Cheng Z, Yu T, Xia J, Wei Y, Wu W, Xie X, Yin W, Li H, Liu M, Xiao Y, Gao H, Guo L, Xie J, Wang G, Jiang R, Gao Z, Jin Q, Wang J, Cao B. 2020. Clinical features of patients infected with 2019 novel coronavirus in Wuhan, China. Lancet 395(10223):497-506 DOI:10.1016/S01406736(20)30183-5, PMID:31986264

Huang SY. (2015). Exploring the potential of global protein-protein docking: an overview and critical assessment of current programs for automatic ab initio docking. Drug Discovery Today, 20(8), 969-977.

Ilinskaya AN, Dobrovolskaia MA. 2016. Understanding the immunogenicity and antigenicity of nanomaterials: Past, present and future. Toxicology and Applied Pharmacology 299:70-77. DOI: 10.1016/j.taap.2016.01.005, PMID: 26773813; PMCID: PMC4811736.

Islam R, Sakib MS, Zaman A. 2012. A computational assay to design an epitope-based peptide vaccine against chikungunya virus. Future virology 7(10):1029-1042. DOI:10.2217/fvl.12.95

Jespersen MC, Peters B, Nielsen M, Marcatili P. 2017. BepiPred-2.0: improving sequencebased B-cell epitope prediction using conformational epitopes. Nucleic Acids Research 45(W1):W24-W29. DOI:10.1093/nar/gkx346

Ji W, Wang W, Zhao X, Zai J, Li X. 2020. Homologous recombination within the spike glycoprotein of the newly identified coronavirus may boost cross-species transmission from snake to human. Journal of Medical Virology 92. DOI:10.1002/jmv.25682.

Peer] reviewing PDF | (2020:04:47510:1:1:NEW 24 Jun 2020) 
808 Lai MMC, Perlman S, Anderson LJ. 2007. Coronaviridae in Knipe DM, Howley PM

809 (Eds.), Fields Virology, Lippincott Williams \& Wilkins. 1305-1335

810 Lapelosa M, Gallicchio E, Arnold GF, Arnold E, Levy RM. 2009. In silico vaccine design based

811 on molecular simulations of rhinovirus chimeras presenting HIV-1 gp41 epitopes. Journal of

812 Molecular Biology 385(2):675-91. doi: 10.1016/j.jmb.2008.10.089, PMID: 19026659; PMCID:

813 PMC2649764.

814 Larsen MV, Lundegaard C, Lamberth K, Buus S, Brunak S, Lund O, Nielsen M. 2005. An

815 integrative approach to CTL epitope prediction: a combined algorithm integrating MHC class I

816 binding, TAP transport efficiency, and proteasomal cleavage predictions. European Journal of

817 Immunology 35(8):2295-2303. DOI:10.1002/eji.200425811, PMID:15997466

818 Larsen MV, Lundegaard C, Lamberth K, Buus S, Lund O, Nielsen M. 2007. Large-scale

819 validation of methods for cytotoxic T-lymphocyte epitope prediction. BMC Bioinformatics

820 8:424. DOI: 10.1186/1471-2105-8-424, PMID: 17973982; PMCID: PMC2194739.

821 Letko M, Marzi A, Munster V. 2020. Functional assessment of cell entry and receptor usage for

822 SARS-CoV-2 and other lineage B betacoronaviruses. Nature Microbiology 5(4):562-569.

823 DOI:10.1038/s41564-020-0688-y, PMID:32094589

824 Li F, Li W, Farzan M, Harrison SC. 2005. Structure of SARS coronavirus spike receptor-binding 825 domain complexed with receptor. Science 309(5742):1864-1868.

826 Li W, Moore MJ, Vasilieva N, Sui J, Wong SK, Berne MA, Somasundaran M, Sullivan JL,

827 Luzuriaga K, Greenough TC, Choe H. 2003. Angiotensin-converting enzyme 2 is a functional

828 receptor for the SARS coronavirus. Nature 426(6965):450-454.

829 Lu G, Hu Y, Wang Q, Qi J, Gao F, Li Y, Zhang Y, Zhang W, Yuan Y, Bao J, Zhang B. 2013.

830 Molecular basis of binding between novel human coronavirus MERS-CoV and its receptor

831 CD26. Nature 500(7461):227-231.

832 Lu G, Wang Q, Gao GF. 2015. Bat-to-human: spike features determining ‘host jump'of

833 coronaviruses SARS-CoV, MERS-CoV, and beyond. Trends in microbiology 23(8):468-478.

834 Lundegaard C, Lamberth K, Harndahl M, Buus S, Lund O, Nielsen M. 2008. NetMHC-3.0:

835 accurate web accessible predictions of human, mouse and monkey MHC class I affinities for

836 peptides of length 8-11. Nucleic Acids Research 36(Web Server issue):W509-12.DOI:

837 10.1093/nar/gkn202, PMID: 18463140; PMCID: PMC2447772. 
838 McKeever TM, Lewis SA, Smith C, Hubbard R. 2004. Vaccination and allergic disease: a birth 839 cohort study. American journal of public health 94(6):985-9. DOI: 10.2105/ajph.94.6.985, 840 PMID: 15249303; PMCID: PMC1448377.

841 Manzin A, Solforosi L, Petrelli E, Macarri G, Tosone G, Piazza M, Clementi M. 1998.

842 Evolution of hypervariable region 1 of hepatitis $\mathrm{C}$ virus in primary infection. Journal of Virology 843 72(7):6271-6276. PMID: 9621104; PMCID: PMC110460.

844 María RAR, Arturo CVJ, Alicia JA, Paulina MLG, and Gerardo AO. 2017.The impact of 845 bioinformatics on vaccine design and development. in Vaccines, F. Afrin, H. Hemeg, and H. 846 Ozbak, Eds., InTech, Rijeka, Croatia. DOI:10.5772/intechopen.69273

847 Menachery VD, Yount BL Jr, Debbink K, Agnihothram S, Gralinski LE, Plante JA, Graham 848 RL, Scobey T, Ge XY, Donaldson EF, Randell SH, Lanzavecchia A, Marasco WA, Shi ZL, 849 Baric RS. 2015. A SARS-like cluster of circulating bat coronaviruses shows potential for human 850 emergence. Nature Medicine 21(12):1508-1513. DOI: 10.1038/nm.3985, PMID: 26552008; 851 PMCID: PMC4797993.

852 Nielsen M, Lundegaard C, Lund O. 2007. Prediction of MHC class II binding affinity using 853 SMM-align, a novel stabilization matrix alignment method. BMC Bioinformatics 8:238. DOI: 854 10.1186/1471-2105-8-238, PMID: 17608956; PMCID: PMC1939856.

855 Oany AR, Emran AA, Jyoti TP. 2014. Design of an epitope-based peptide vaccine against spike 856 protein of human coronavirus: an in silico approach. Drug design, development and therapy.

857 8:1139.

858 Patronov A, Doytchinova I. 2013. T-cell epitope vaccine design by immunoinformatics. Open 859 Biology 3(1):120139. DOI: 10.1098/rsob.120139, PMID: 23303307; PMCID: PMC3603454.

860 Peters B, Sidney J, Bourne P, Bui HH, Buus S, Doh G, Fleri W, Kronenberg M, Kubo R, Lund 861 O, Nemazee D, Ponomarenko JV, Sathiamurthy M, Schoenberger SP, Stewart S, Surko P, Way 862 S, Wilson S, Sette A. 2005. The design and implementation of the immune epitope database and 863 analysis resource. Immunogenetics 57(5):326-336. DOI: 10.1007/s00251-005-0803-5, PMID: 864 15895191; PMCID: PMC4780685.

865 Peters B, Bulik S, Tampe R, van Endert PM, Holzhütter H-G. 2003.Identifying MHC class I 866 epitopes by predicting the TAP transport efficiency of epitope precursors. Journal of 867 Immunology 171(4):1741-1749. DOI:10.4049/jimmunol.171.4.1741

868 Petsko GA, Ringe D: Protein structure and function. Blackwell Publishing; 2004. 
869 Pickett BE, Sadat EL, Zhang Y, Noronha JM, Squires RB, Hunt V, Liu M, Kumar S, Zaremba

870 S, Gu Z, Zhou L, Larson CN, Dietrich J, Klem EB, Scheuermann RH. 2012. ViPR: an open

871 bioinformatics database and analysis resource for virology research. Nucleic Acids Research,

872 409(D1):D593-D598. DOI:10.1093/nar/gkr859

873 Ponomarenko J,Bui H H, Li W, Fusseder N, Bourne P E, Sette A \& Peters B. 2008. ElliPro: a

874 new structure-based tool for the prediction of antibody epitopes. BMC Bioinformatics 9:514.

875 DOI:10.1186/1471-2105-9-514

876 Purcell AW, McCluskey J, Rossjohn J. 2007. More than one reason to rethink the use of

877 peptides in vaccine design. Nature Reviews Drug Discovery 6(5):404-414.

878 DOI:10.1038/nrd2224, PMID:17473845

879 PyMOL: The PyMOL Molecular Graphics System, Version 2.3.4 Schrödinger, LLC.

880 Rodrigues JP, Bonvin AM. 2014. Integrative computational modeling of protein

881 interactions. The FEBS journal 281(8):1988-2003.

882 Sarkander J, Hojyo S, Tokoyoda K. 2016. Vaccination to gain humoral immune memory.

883 Clinical \& Translational Immunology 5(12):e120. DOI: 10.1038/cti.2016.81. PMID: 28090322;

884 PMCID: PMC5192068.

885 Seib KL, Zhao X, Rappuoli R. 2012. Developing vaccines in the era of genomics: a decade of

886 reverse vaccinology. Clinical Microbiology and Infection 18:109-116. DOI:10.1111/j.1469-

887 0691.2012.03939.x , PMID:22882709

888 Shang J, Ye G, Shi K, Wan Y, Luo C, Aihara H, Geng Q, Auerbach A, Li F. 2020. Structural

889 basis of receptor recognition by SARS-CoV-2. Nature 30:1-4.

890 Shen Y, Maupetit J, Derreumaux P, and Tufféry P. 2014. Improved PEP-FOLD approach for

891 peptide and miniprotein structure prediction. Journal of Chemical Theory and Computation

892 10(10):4745-4758. DOI:10.1021/ct500592m

893 Shereen MA, Khan S, Kazmi A, Bashir N, Siddique R. 2020. COVID-19 infection: origin,

894 transmission, and characteristics of human coronaviruses. Journal of Advanced Research.

895 Singh H, Ansari HR, Raghava GP. 2013. Improved method for linear B-cell epitope prediction 896 using antigen's primary sequence. PLoS One 8(5):e62216. DOI: 10.1371/journal.pone.0062216,

897 PMID: 23667458; PMCID: PMC3646881. 
898 Song Z, Xu Y, Bao L, Zhang L, Yu P, Qu Y, Zhu H, Zhao W, Han Y, Qin C. 2019. From SARS

899 to MERS, Thrusting Coronaviruses into the Spotlight. Viruses 11(1):59. doi:

900 10.3390/v11010059, PMID: 30646565; PMCID: PMC6357155.

901 Stern LJ, Wiley DC. 1994. 1994. Antigenic peptide binding by class I and class II

902 histocompatibility proteins. Structure 2(4):245-251. DOI:10.1016/s0969-2126(00)00026-5,

903 PMID:8087551

904 Sun P, Ju H, Liu Z, Ning Q, Zhang J, Zhao X, Huang Y, Ma Z, Li Y. 2013. Bioinformatics

905 resources and tools for conformational B-cell epitope prediction. Computational and

906 Mathematical Methods in Medicine 2013:943636. DOI: 10.1155/2013/943636, PMID:

907 23970944; PMCID: PMC3736542.

908 Taguchi F, Hirai-Yuki A. 2012. Mouse hepatitis virus receptor as a determinant of the mouse 909 susceptibility to MHV infection. Frontiers in microbiology 24;3:68.

910 Tenzer S, Peters B, Bulik S, Schoor O, Lemmel C, Schatz M, Kloetzel P-M, Rammensee H-G,

911 Schild H, Holzhütter H-G. 2005. Modeling the MHC class I pathway by combining predictions

912 of proteasomal cleavage, TAP transport and MHC class I binding. Cellular and molecular life

913 sciences : CMLS 62(9):1025-1037. DOI:10.1007/s00018-005-4528-2.

914 Thévenet P, Shen Y, Maupetit J, Guyon F, Derreumaux P, Tufféry P. 2012. PEP-FOLD: an

915 updated de novo structure prediction server for both linear and disulfide bonded cyclic peptides.

916 Nucleic Acids Research 40(W1):W288-293. DOI: 10.1093/nar/gks419, PMID: 22581768;

917 PMCID: PMC3394260.

918 Toseland CP, Clayton DJ, McSparron H, Hemsley SL, Blythe MJ, Paine K, Doytchinova IA,

919 Guan P, Hattotuwagama CK, Flower DR. 2005. AntiJen: a quantitative immunology database

920 integrating functional, thermodynamic, kinetic, biophysical, and cellular data. Immunome

921 Research 1:4. DOI: 10.1186/1745-7580-1-4.

922 Twiddy SS, Holmes EC, Rambaut A. 2003. Inferring the rate and time-scale of dengue virus

923 evolution. Molecular Biology and Evolution 20(1):122-129. DOI:10.1093/molbev/msg010,

924 PMID:12519914

925 Van Regenmortel MHV. 2001. Antigenicity and immunogenicity of synthetic peptides.

926 Biologicals 29(3-4):209-213. DOI:10.1006/biol.2001.0308 
927 Van Zundert GC, Rodrigues JP, Trellet M, Schmitz C, Kastritis PL, Karaca E, Melquiond AS, 928 van Dijk M, De Vries SJ, Bonvin AM. 2016. The HADDOCK2. 2 web server: user-friendly 929 integrative modeling of biomolecular complexes. Journal of molecular biology 428(4): 720-725.

930 Wallace AC, Laskowski RA, Thornton JM. 1995. LIGPLOT: A program to generate schematic 931 diagrams of protein-ligand interactions. Protein Engineering 8: 127-134.

932 Wu K, Li W, Peng G, Li F. 2009. Crystal structure of NL63 respiratory coronavirus receptor933 binding domain complexed with its human receptor. Proceedings of the National Academy of 934 Sciences $106(47): 19970-19974$.

935 Zhou P, Yang XL, Wang XG, Hu B, Zhang L, Zhang W, Si HR, Zhu Y, Li B, Huang CL, Chen 936 HD. 2020a. A pneumonia outbreak associated with a new coronavirus of probable bat origin. 937 Nature 579 (7798):270-273. 
Figure 1

Schematic representation of methods adopted in the study

Figure 1 : Schematic representation of epitope-based vaccine design from the structural proteins of SARS-CoV-2. 


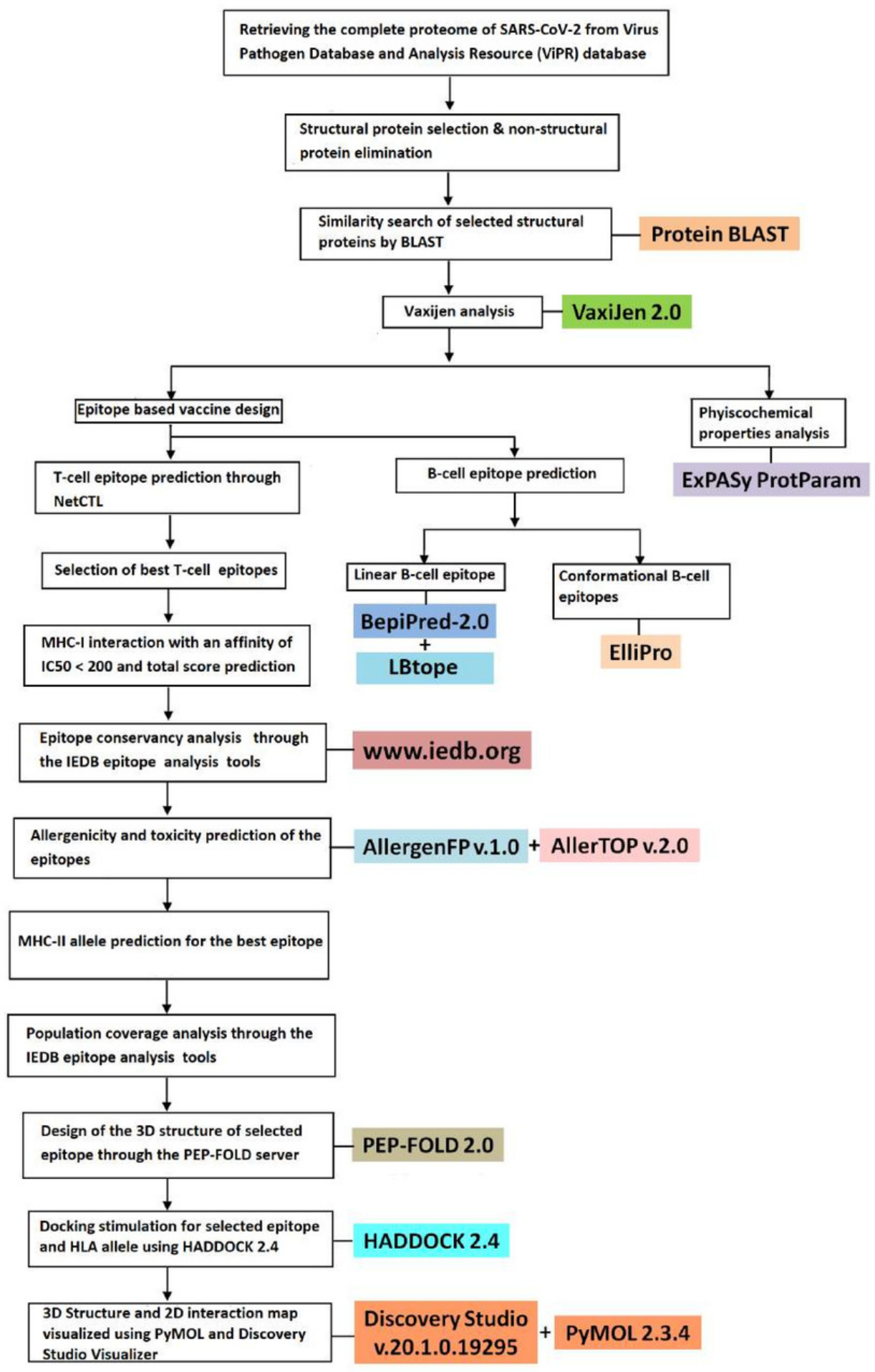




\section{Figure 2}

Docking simulation of $\mathrm{CD} 8+\mathrm{T}$ cell epitopes with $\mathrm{MHCl}$ alleles

Figure 2: Docking simulation study of MHC I epitopes: HADDOCK 2.4 was used for the docking of MHC I epitopes with the corresponding HLA allele. 3D structures of best clusters were then visualized using PYMOL 2.3.4 and 2D interaction map was visualized using Discovery Studio tools. Images pertaining to epitopes from Surface Glycoprotein or spike protein (a-h); (a) 3D structure of surface of the chain ' $A$ ' of MHC-I HLA allele "HLA-C*07:02" and the sticky form of epitope "PYRVVVLSF" from spike protein (b) epitope "PYRVVVLSF" and the chain 'A' of HLA-C*07:02 in 3D cartoon structure (c) Sticky form of epitope "PYRVVVLSF" with positions of residues $(d) * * 2 D$ interaction map of epitope "PYRVVVLSF" and the residues from chain 'A' of HLA-C*07:02 (e) 3D structure of surface of the chain 'A' "HLA-C*07:02" and the sticky form of epitope "QLTPTWRVY" from Spike protein (f) epitope "QLTPTWRVY" and the chain 'A' of "HLA-C*07:02" in 3D cartoon structure (g) Sticky form of epitope "QLTPTWRVY" with residue's position (h) 2D interaction map of epitope "QLTPTWRVY" and the residues from chain 'A' of HLA-C*07:02. Images pertaining to an epitope from ORF3a protein (i-I); (i) 3D structure of surface of the chain ' $A$ ' of "HLA-A*30:01" and the sticky form of epitope "HVTFFIYNK" from ORF3a protein (j) epitope "HVTFFIYNK" and the chain 'A' of "HLA-A*30:01" in 3D cartoon structure (k) Sticky form of epitope "HVTFFIYNK" with positions of residues (I) 2D interaction map of epitope "HVTFFIYNK" and the residues from chain ' $A$ ' of HLA-A*30:01. Images of an epitope from Membrane glycoprotein (m-p); (m) 3D structure of surface of the chain ' $A$ ' of "HLAB*58:01" and the sticky form of epitope "LTWICLLQF" from membrane protein (n) Epitope "LTWICLLQF" and the chain 'A' of "HLA-B*58:01" in 3D cartoon structure (0) sticky form of epitope "LTWICLLQF" with residue's position (p) 2D interaction map of epitope "LTWICLLQF" and the residues from chain ' $A$ ' of $H L A-B * 58: 01$. Images of an epitope from Nucleocapsid 
phosphoprotein (q-t); (q) 3D structure of surface of the chain ' $A$ ' of "HLA-B*08:01" and the sticky form of epitope "SPRWYFYYL" from Nucleocapsid phosphoprotein ( $r$ ) Epitope "SPRWYFYYL" and the chain 'A' of "HLA-B*08:01" in the 3D cartoon structure (s) Sticky form of epitope "SPRWYFYYL" with residue's position (t) 2D interaction map of epitope "SPRWYFYYL" and the residues from chain 'A' of HLA-B*8:01. ** In all 2 D interaction diagram colours depict different types of interactions (i) Green colour - Hydrogen Bond (classical, Non classical) (ii) Orange colour - Electrostatic (salt Bridge, Charge, pi-charge) (iii) Pink colour Hydrophobic (Pi hydrophobic, Alkyl hydrophobic, Mixed pi/Alkyl hydrophobic) (iv) White colour- Carbon Hydrogen bond (v) Red colour - unfavorable (Charge Replusion, Acceptor/Donor clash)

Surface Glycoprotein $(\mathrm{a}-\mathrm{h})$

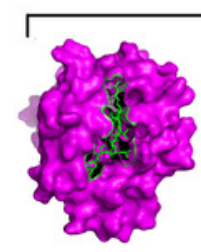

(a)

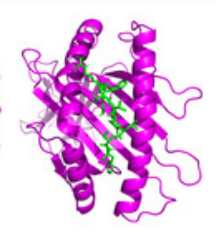

(b)

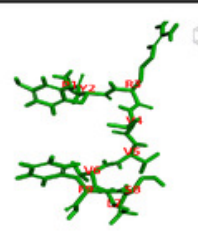

(c)

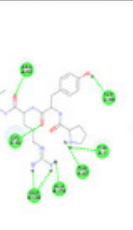

(d)

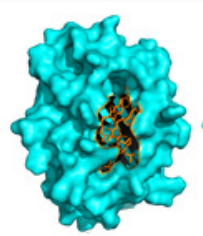

(e)

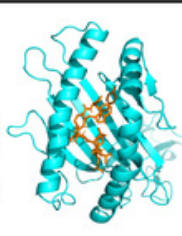

(f)

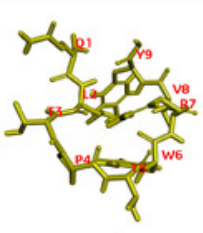

(g)

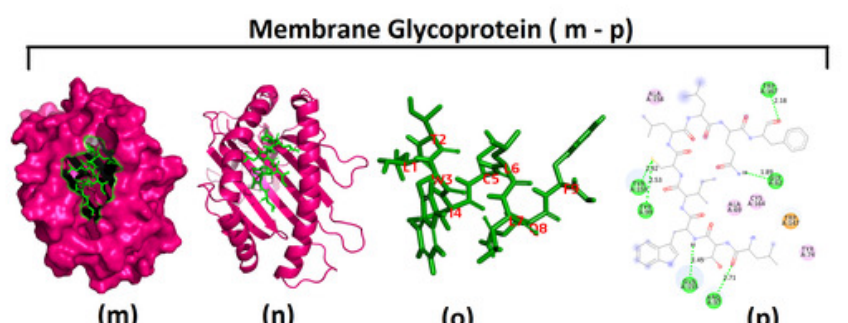

(o)

(p)

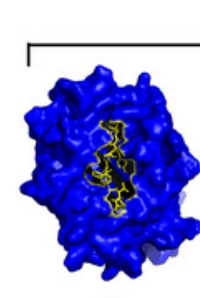

(i) (j)
ORF3a Protein ( $\mathrm{i}-\mathrm{I})$

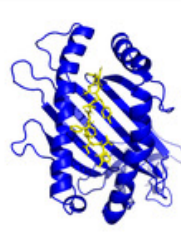

(k)
(I)

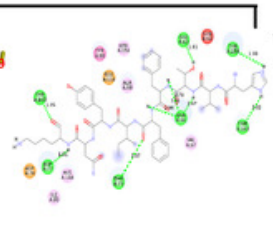

Nucleocapsid Phosphoprotein ( $q-t$ )

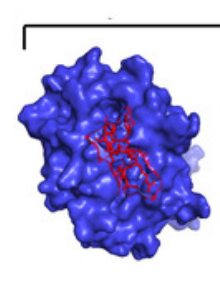

(q)

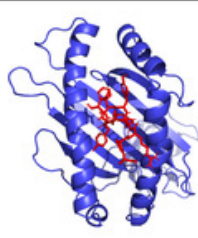

(r)

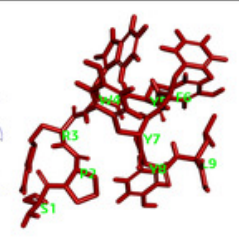

(s)

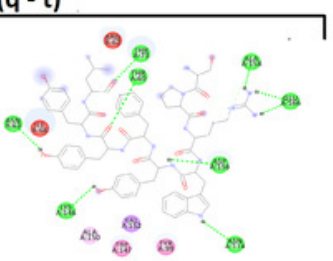

(t) 


\section{Figure 3}

Docking simulation of CD4+ T cell epitopes with MHC II alleles

Figure 3: Docking simulation study of MHC II epitopes: HADDOCK 2.4 was used for the docking of MHC II epitopes with the corresponding HLA allele. 3D structures of best clusters were then visualized using PYMOL 2.3.4 and 2D interaction map was

\section{visualized using Ligplot $^{+}$v.1.4.5. Images pertaining to epitopes from Surface}

Glycoprotein or spike protein (a-d); (a) 3D structure of surface of the chain 'A' \& 'B' from MHC-II HLA allele, "HLA-DRB1*01:01" and the sticky form of epitope "TNGVGYQPYRVVVLS" from spike protein (b) epitope "TNGVGYQPYRVVVLS" and both the chains from HLADRB1*01:01 in 3D cartoon structure (c) Sticky form of epitope "TNGVGYQPYRVVVLS" with positions of residues (d)** 2D interaction map of epitope "TNGVGYQPYRVVVLS" and the residues from both chain ' $A$ ' \& ' $B$ ' of HLA-DRB1*01:01. Images pertaining to epitopes from ORF3a protein (e-h) (e) 3D structure of surface of the two chains A \& B of "HLADRB1*01:01" and the sticky form of epitope "ITLKKRWQLALSKGV" from ORF3a protein (f) epitope "ITLKKRWQLALSKGV" and both the chains of HLA-DRB1*01:01 in 3D cartoon structure (g) Sticky form of epitope "ITLKKRWQLALSKGV" with positions of residues (h) 2D interaction map of epitope "ITLKKRWQLALSKGV" and the residues from the chains $A \& B$ of HLA-DRB1*01:01. Images of an epitope from Membrane glycoprotein (i-I); (i) 3D structure of surface of the chains A \& B from "HLA-DRB1*04:01" allele and the sticky form of epitope "LFLTWICLLQFAYAN" from membrane glycoprotein (j) epitope "LFLTWICLLQFAYAN" and the chains A \& B from HLA-DRB1*04:01 in 3D cartoon structure $(k)$ Sticky form of epitope "LFLTWICLLQFAYAN" with positions of residues (I) 2D interaction map of epitope "LFLTWICLLQFAYAN" and the residues from A \& B chain of HLA-DRB1*04:01. ** In all $2 \mathrm{D}$ interaction diagram colours depict different types of Bonds (i) Purple -ligand bonds (ii) 
Orange-Non-ligand bonds (iii) Olive green-Hydrogen Bonds (iv) Brick red-Hydrophobic Bonds. The atoms are also depicted by color in; Blue-Nitrogen; Red-Oxygen; Black-Carbon; YellowSulphur; Turquoise-Water; Purple-Phosphorous; Pink-Metal; Lime green-Other atom. Brick red denotes hydrophobic residue. 


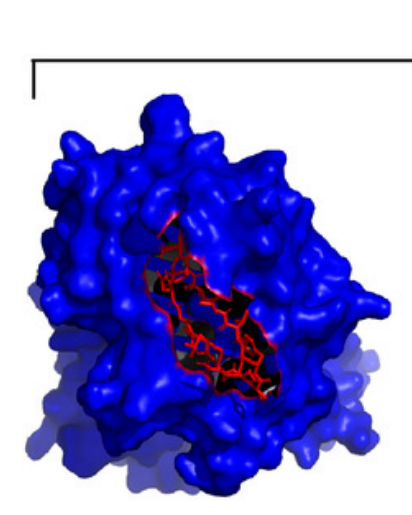

(a)

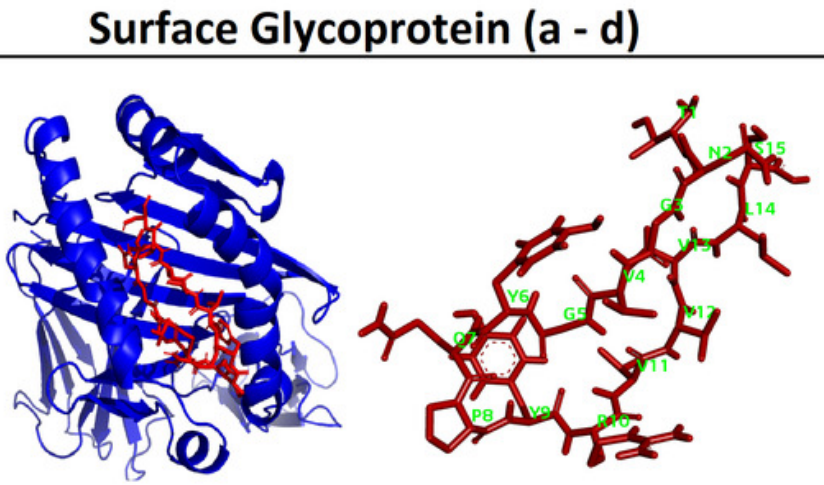

(b) (c)

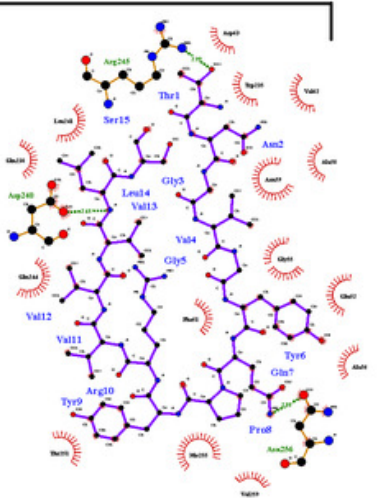

(d)

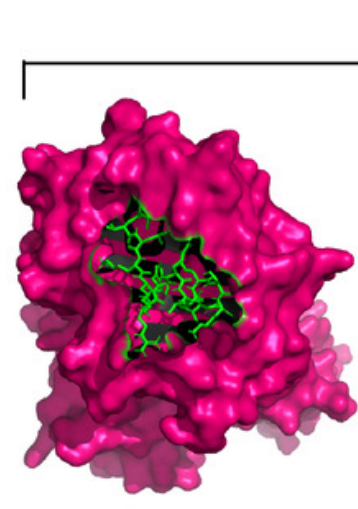

(e) (f)

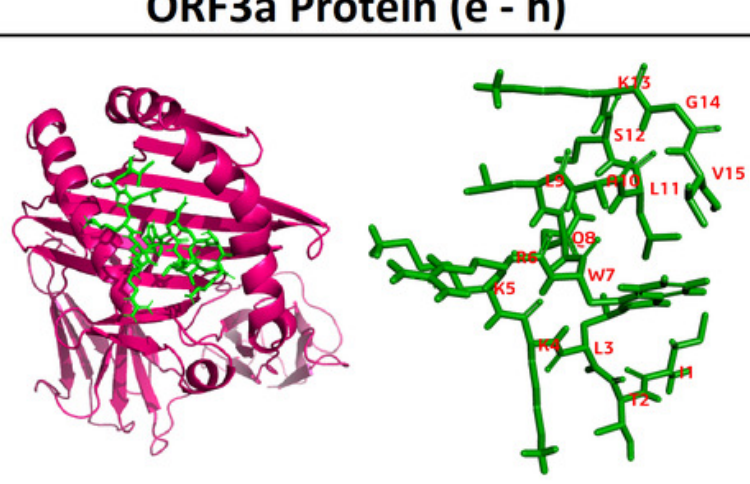

(g)

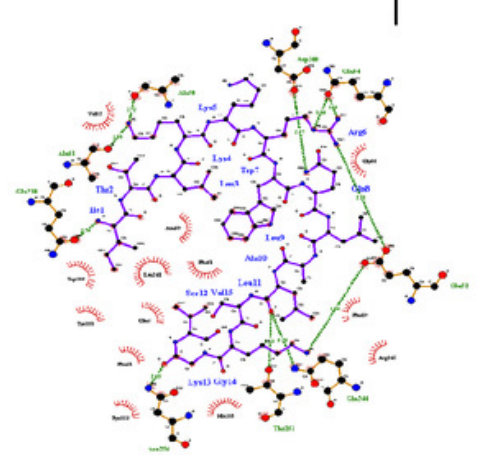

(h)

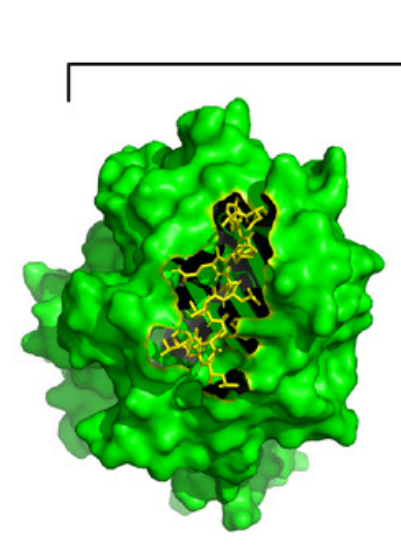

(i)

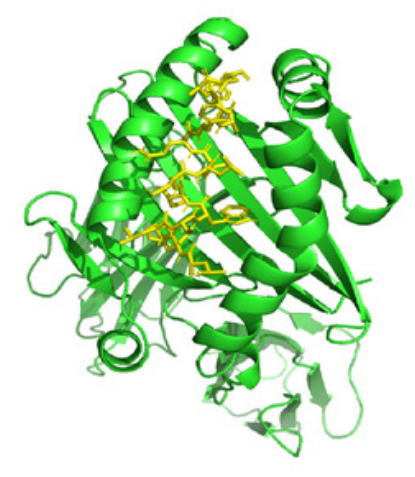

(j)

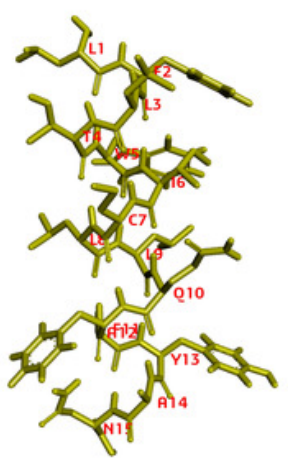

(k)

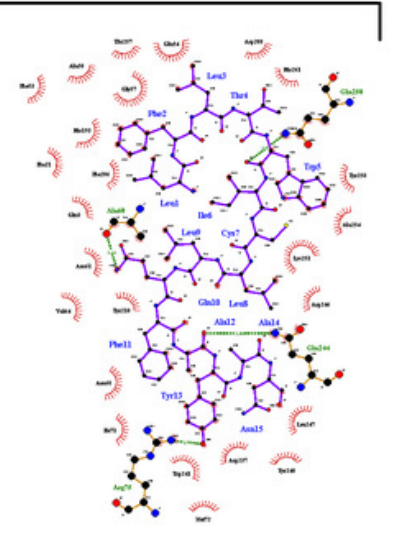

(I) 


\section{Figure 4}

Three-dimensional representation of B cell conformational epitopes

Figure 4: Three-dimensional representation of B cell conformational epitopes of the structural proteins of SARS-CoV-2. The epitopes are represented by 3D structure, and the bulk of the protein is represented by sticks. (a-d) images are of the surface glycoprotein, (e-f) images are of ORF3a Protein, $(\mathrm{g}-\mathrm{h})$ images are of membrane glycoprotein and (i-j) images are of Nucleocapsid Phosphoprotein. 
Surface Glycoprotein (a - d)

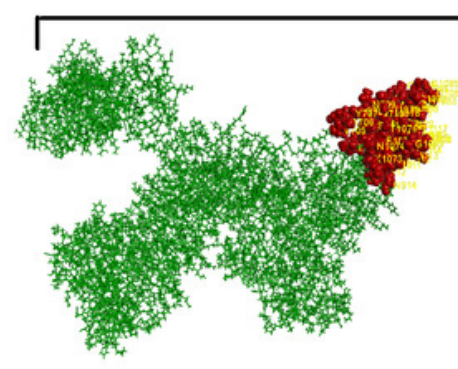

(a)

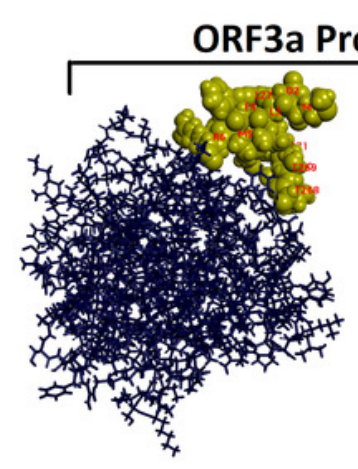

(e)

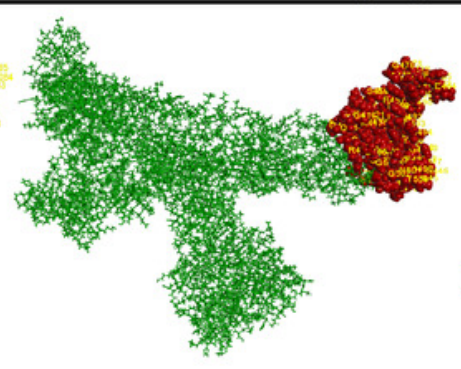

(b)

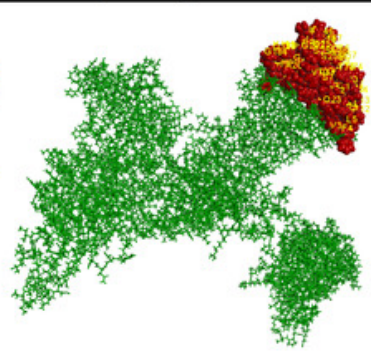

(c)

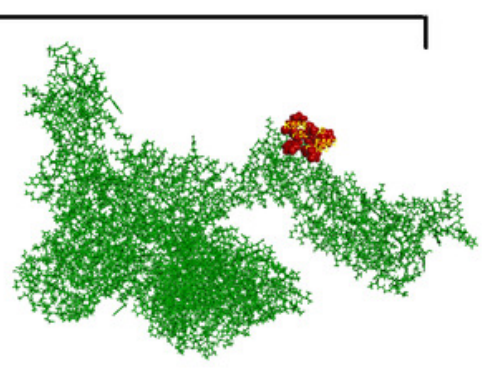

(d)

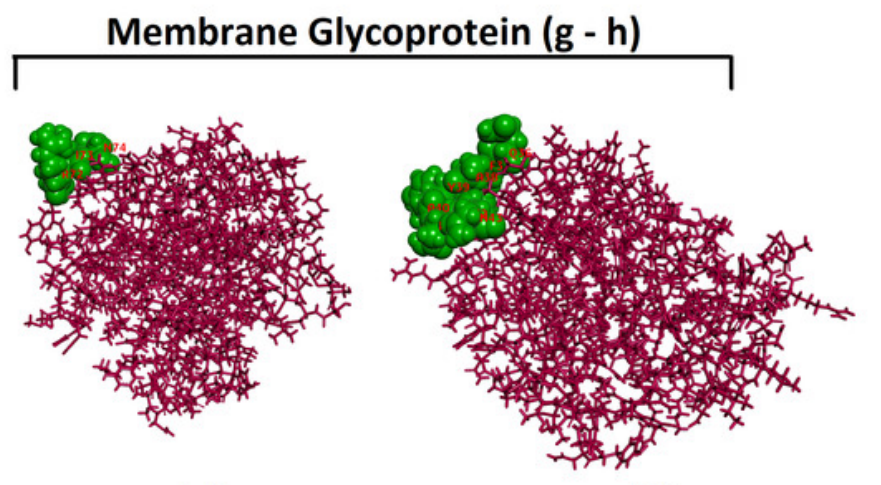

(g)

(h)

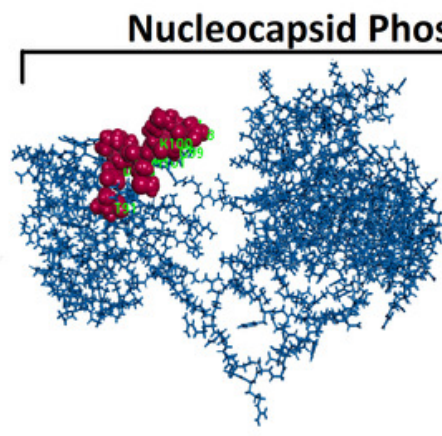

(i)

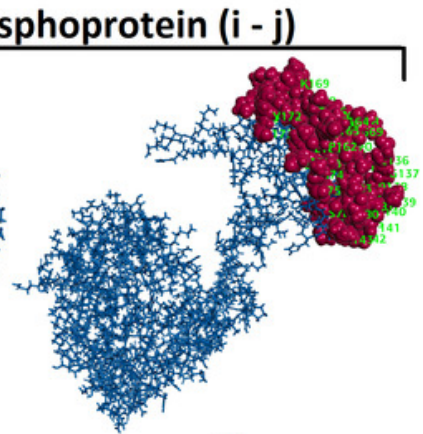

(j) 


\section{Table $\mathbf{1}$ (on next page)}

Potential T cell epitopes from different structural proteins from SARS-CoV-2

Table 1: The potential T-cell epitopes with interacting MHC-I alleles and antigenicity, immunogenicity and conservancy scores derived from Structural proteins of SARS-CoV-2. Most promising proposed vaccine epitopes are highlighted. 


\section{Table-1}

\begin{tabular}{|c|c|c|c|c|c|c|c|c|}
\hline \multicolumn{9}{|c|}{ Surface glycoprotein (S) } \\
\hline \multirow[t]{2}{*}{ Epitopes } & \multirow[t]{2}{*}{ Position } & \multirow{2}{*}{$\begin{array}{l}\text { Antigenicity } \\
\text { (Vaxijen } \\
\text { Score) }\end{array}$} & \multirow[t]{2}{*}{ MHC-I alleles } & \multirow[t]{2}{*}{ Immunogenicity } & \multirow[t]{2}{*}{ Conservancy } & \multicolumn{2}{|c|}{ Allergenicity } & \multirow[t]{2}{*}{ Toxicity } \\
\hline & & & & & & AllerTOP & AllergenFP & \\
\hline YQPYRVVVL & $505-513$ & 0.5964 & $\begin{array}{c}\text { HLA-C*12:03,HLA-A*02:06,HLA- } \\
\text { B*39:01,HLA-B*15:02,HLA- } \\
\text { B*15:01,HLA-C*14:02,HLA- } \\
\text { C*03:03 }\end{array}$ & 0.14090 & $100.00 \%$ & NO & NO & NT \\
\hline PYRVVVLSF & $507-515$ & 1.0281 & $\begin{array}{c}\text { HLA-C*14:02,HLA-A*23:01,HLA- } \\
\text { C*12:03,HLA-C*07:02,HLA- } \\
\text { B*15:02,HLA-A*24:02 }\end{array}$ & 0.03138 & $100.00 \%$ & NO & NO & NT \\
\hline AEIRASANL & $1016-1024$ & 0.7082 & $\begin{array}{c}\text { HLA-C*03:03,HLA-B*40:01,HLA- } \\
\text { B*15:02,HLA-C*12:03,HLA- }^{*} \text { - }{ }^{*} 40: 02, \text { HLA-B*44:03 }\end{array}$ & 0.00689 & $100.00 \%$ & NO & YES & NT \\
\hline FLHVTYVPA & $1062-1070$ & 1.3346 & $\begin{array}{c}\text { HLA-C*03:03,HLA-C*14:02,HLA- } \\
\text { C*12:03,HLA-A*02:01,HLA- } \\
\text { A*02:06,HLA-B*15:02 }\end{array}$ & 0.11472 & $88.89 \%$ & YES & YES & NT \\
\hline IAIPTNFTI & $712-720$ & 0.7052 & $\begin{array}{c}\text { HLA-C*03:03,HLA-C*12:03,HLA- } \\
\text { B*58:01,HLA-B*53:01,HLA- } \\
\text { C*15:02,HLA-A*02:06 }\end{array}$ & 0.18523 & $88.89 \%$ & NO & YES & NT \\
\hline WPWYIWLGF & $1212-1220$ & 1.4953 & $\begin{array}{c}\text { HLA-B*35:01,,HLA-B*53:01,HLA- } \\
C^{*} 12: 03, \text { HLA-B*07:02,HLA- } \\
B^{*} 15: 02\end{array}$ & 0.41673 & $88.89 \%$ & YES & YES & NT \\
\hline QYIKWPWYI & $1208-1216$ & 1.4177 & $\begin{array}{c}\text { HLA-A*23:01,HLA-C*12:03,HLA- } \\
\text { C*14:02,HLA-A*24:02,HLA- } \\
\text { C*03:03 }\end{array}$ & 0.21624 & $88.89 \%$ & YES & NO & NT \\
\hline GQTGKIADY & $413-421$ & 1.4019 & $\begin{array}{l}\text { HLA-C*03:03, HLA-C*12:03,HLA- } \\
\text { A*30:02 }\end{array}$ & 0.00796 & $88.89 \%$ & NO & YES & NT \\
\hline GVYFASTEK & $89-97$ & 0.7112 & $\begin{array}{l}\text { HLA-C*03:03,HLA-A*11:01,HLA- } \\
\text { C*12:03,HLA-A*03:01,HLA- } \\
\text { C*14:02,HLA-C*15:02,HLA- }\end{array}$ & 0.09023 & $77.78 \%$ & NO & NO & NT \\
\hline
\end{tabular}




\begin{tabular}{|c|c|c|c|c|c|c|c|c|}
\hline & & & A*68:01,HLA-A*30:01 & & & & & \\
\hline VTYVPAQEK & $1065-1073$ & 0.8132 & $\begin{array}{c}\text { HLA-C*03:03,HLA-C*15:02,HLA- } \\
\text { C*1 }^{*}: 03, \text { HLA-C*14:02,HLA- } \\
\text { A*11:01,HLA-A*03:01,HLA- }^{*} \text { A*30:01 }\end{array}$ & 0.02711 & $77.78 \%$ & YES & YES & NT \\
\hline PFFSNVTWF & $57-65$ & 0.6638 & $\begin{array}{c}\text { HLA-C*12:03,HLA-C*14:02,HLA- } \\
\text { C*07:02,HLA-B*15:02,HLA- }^{*} \text { - }{ }^{*} 23: 01, \text { HLA-C*03:03 }\end{array}$ & 0.06627 & $77.78 \%$ & YES & YES & NT \\
\hline QLTPTWRVY & $628-636$ & 1.2119 & $\begin{array}{c}\text { HLA-C*03:03,HLA-C*12:03,HLA- } \\
\text { C*14:02,HLA-B*15:02,HLA- } \\
\text { C*07:02 }\end{array}$ & 0.31555 & $77.78 \%$ & NO & NO & NT \\
\hline VYAWNRKRI & $350-358$ & 0.5003 & $\begin{array}{c}\text { HLA-C*14:02,HLA-C*12:03,HLA- } \\
\text { C*03:03,HLA-A*23:01,HLA- } \\
\text { A*24:02 }\end{array}$ & 0.12625 & $77.78 \%$ & YES & YES & NT \\
\hline \multicolumn{9}{|c|}{ Orf3A Protein } \\
\hline \multirow[t]{2}{*}{ Epitopes } & \multirow[t]{2}{*}{ Position } & \multirow[t]{2}{*}{ Antigenicity } & \multirow[t]{2}{*}{ MHC-I alleles } & \multirow[t]{2}{*}{ Immunogenicity } & \multirow[t]{2}{*}{ Conservancy } & \multicolumn{2}{|c|}{ Allergenicity } & \multirow[t]{2}{*}{ Toxicity } \\
\hline & & & & & & AllerTOP & AllergenFP & \\
\hline LKKRWQLAL & $65-73$ & 1.0692 & $\begin{array}{c}\text { HLA-C*12:03,HLA-B*15:02,HLA- } \\
\text { C*03:03 }\end{array}$ & 0.10224 & $88.89 \%$ & NO & NO & NT \\
\hline HVTFFIYNK & $227-235$ & 0.9862 & $\begin{array}{c}\text { HLA-A*68:01, HLA-A*11:01, HLA- } \\
\text { C*12:03, HLA-A*30:01, HLA- } \\
\text { A*31:01, HLA-C*03:03, HLA- } \\
\text { A*03:01 }\end{array}$ & 0.36278 & $66.67 \%$ & NO & NO & NT \\
\hline YQIGGYTEK & $184-192$ & 1.0504 & $\begin{array}{l}\text { HLA-C*12:03,HLA-A*02:06,HLA- } \\
\text { C*03:03 }\end{array}$ & 0.19808 & $77.78 \%$ & NO & YES & NT \\
\hline \multicolumn{9}{|c|}{ Envelope protein (E) } \\
\hline \multirow[t]{2}{*}{ Epitopes } & \multirow[t]{2}{*}{ Position } & \multirow[t]{2}{*}{ Antigenicity } & \multirow[t]{2}{*}{ MHC-I alleles } & \multirow[t]{2}{*}{ Immunogenicity } & \multirow[t]{2}{*}{ Conservancy } & \multicolumn{2}{|c|}{ Allergenicity } & \multirow[t]{2}{*}{ Toxicity } \\
\hline & & & & & & AllerTOP & AllergenFP & \\
\hline LLFLAFVVF & $18-26$ & 0.8144 & $\begin{array}{c}\text { HLA-B*15:01,HLA-A*32:01,HLA- } \\
C^{*} 12: 03, \text { HLA-C*14:02,HLA- } \\
\text { B*15:02,HLA-C*03:03,HLA- }^{*} \text { A*02:06 }\end{array}$ & 0.23410 & $100 \%$ & NO & YES & NT \\
\hline FLLVTLAIL & $26-34$ & 0.9645 & $\begin{array}{c}\text { HLA-C*03:03,HLA-A*02:01,HLA- } \\
\text { B*15:02,HLA-C*14:02,HLA- }\end{array}$ & 0.17608 & $100 \%$ & NO & YES & NT \\
\hline
\end{tabular}




\begin{tabular}{|c|c|c|c|c|c|c|c|c|}
\hline & & & A*02:06,HLA-C*12:03 & & & & & \\
\hline FLAFVVFLL & $20-28$ & 0.5308 & $\begin{array}{c}\text { HLA-A*02:01,HLA-A*02:06,HLA- } \\
\text { B*15:02,HLA-C*03:03,HLA- } \\
\text { A*68:02,HLA-C*12:03 }^{*}\end{array}$ & 0.30188 & $100 \%$ & NO & YES & NT \\
\hline VFLLVTLAI & $25-33$ & 0.8134 & $\begin{array}{c}\text { HLA-C*14:02,HLA-C*12:03,HLA- } \\
\text { A*23:01,HLA-C*03:03 }\end{array}$ & 0.07548 & $100 \%$ & NO & YES & NT \\
\hline \multicolumn{9}{|c|}{ Membrane glycoprotein (M) } \\
\hline \multirow[t]{2}{*}{ Epitopes } & \multirow[t]{2}{*}{ Position } & \multirow[t]{2}{*}{ Antigenicity } & \multirow[t]{2}{*}{ MHC-I alleles } & \multirow[t]{2}{*}{ Immunogenicity } & \multirow[t]{2}{*}{ Conservancy } & \multicolumn{2}{|c|}{ Allergenicity } & \multirow[t]{2}{*}{ Toxicity } \\
\hline & & & & & & AllerTOP & AllergenFP & \\
\hline LAAVYRINW & $67-75$ & 1.4322 & $\begin{array}{c}\text { HLA-B*58:01,HLA-C*12:03,HLA- } \\
\text { C*03:03,HLA-B*53:01,HLA- } \\
\text { B*57:01 }\end{array}$ & 0.20790 & $100.00 \%$ & YES & YES & NT \\
\hline LWPVTLACF & $57-65$ & 1.1590 & $\begin{array}{c}\text { HLA-C*14:02,HLA-C*12:03,HLA- } \\
\text { A*24:02,HLA-A*23:01,HLA- }^{*} \text { B }^{*} 15: 02\end{array}$ & 0.06682 & $100.00 \%$ & NO & YES & NT \\
\hline LWLLWPVTL & $54-62$ & 0.7197 & $\begin{array}{c}\text { HLA-C*03:03,HLA-C*12:03,HLA- } \\
\text { B*15:02,HLA-A*23:01,HLA- } \\
\text { C*14:02 }\end{array}$ & 0.24802 & $100.00 \%$ & YES & NO & NT \\
\hline FAYANRNRF & $37-45$ & 0.7785 & $\begin{array}{c}\text { HLA-C*03:03,HLA-C*12:03,HLA- } \\
\text { B }^{*} 15: 02, \mathrm{HLA}-\mathrm{B}^{*} 35: 01, \mathrm{HLA}- \\
\text { C*14:02,HLA-B*53:01 }\end{array}$ & 0.10537 & $88.89 \%$ & YES & YES & NT \\
\hline SYFIASFRL & $94-102$ & 0.4821 & $\begin{array}{c}\text { HLA-B*15:02,HLA-C*14:02,HLA- } \\
\text { C*12:03,HLA-C*07:02,HLA- } \\
\text { A*23:01,HLA-A*24:02 }\end{array}$ & 0.18333 & $88.89 \%$ & NO & YES & NT \\
\hline KLIFLWLLW & $50-58$ & 0.4968 & $\begin{array}{c}\text { HLA-B*58:01,HLA-A*32:01,HLA- } \\
\text { C*12:03,HLA-B*57:01 }\end{array}$ & 0.34287 & $88.89 \%$ & NO & YES & NT \\
\hline RFLYIIKLI & $44-52$ & 0.4257 & $\begin{array}{c}\text { HLA-C*03:03,HLA-C*14:02,HLA- } \\
\text { C*12:03,HLA-A*23:01 }\end{array}$ & 0.05908 & $88.89 \%$ & NO & NO & NT \\
\hline LYIIKLIFL & $46-64$ & 0.4865 & $\begin{array}{l}\text { HLA-C*14:02,HLA-C*03:03,HLA- } \\
\text { C*12:03 }\end{array}$ & 0.13740 & $88.89 \%$ & NO & YES & NT \\
\hline LTWICLLQF & $29-37$ & 1.1393 & $\begin{array}{l}\text { HLA-C*14:02,HLA-B*58:01,HLA- } \\
\quad \text { C }^{*} 12: 03, \text { HLA-A } * 32: 01\end{array}$ & 0.06584 & $77.78 \%$ & NO & NO & NT \\
\hline \multicolumn{9}{|c|}{ ORF6 protein } \\
\hline Epitopes & Position & Antigenicity & MHC-I alleles & Immunogenicity & Conservancy & \multicolumn{2}{|c|}{ Allergenicity } & Toxicity \\
\hline
\end{tabular}




\begin{tabular}{|c|c|c|c|c|c|c|c|c|}
\hline & & & & & & AllerTOP & AllergenFP & \\
\hline HLVDFQVTI & $23-31$ & 1.4119 & $\begin{array}{l}\text { HLA-C*12:03,HLA-A*29:02,HLA- } \\
\text { C*05:01,HLA-A*30:02 }\end{array}$ & 0.09820 & $100.00 \%$ & YES & NO & NT \\
\hline LLIIMRTFK & $3-11$ & 0.4377 & $\begin{array}{l}\text { HLA-C*12:03, HLA-C*03:03,HLA- } \\
\text { A*32:01, HLA-A*02:01 }\end{array}$ & 0.15600 & $77.78 \%$ & NO & YES & NT \\
\hline \multicolumn{9}{|c|}{ Nucleocapsid phosphoprotein (N) } \\
\hline \multirow[t]{2}{*}{ Epitopes } & \multirow[t]{2}{*}{ Position } & \multirow[t]{2}{*}{ Antigenicity } & \multirow[t]{2}{*}{ MHC-I alleles } & \multirow[t]{2}{*}{ Immunogenicity } & \multirow[t]{2}{*}{ Conservancy } & \multicolumn{2}{|c|}{ Allergenicity } & Toxicity \\
\hline & & & & & & AllerTOP & AllergenFP & \\
\hline KTFPPTEPK & $361-369$ & 0.7571 & $\begin{array}{c}\text { HLA-A*30:01,HLA-C*12:03,HLA- } \\
\text { C*14:02,HLA-A*03:01,HLA- } \\
\text { A*31:01, HLA-A*68:01,HLA- } \\
\text { C*03:03,HLA-A*32:01,HLA- } \\
\text { A*11:01 }\end{array}$ & 0.13060 & $100.00 \%$ & NO & NO & NT \\
\hline LSPRWYFYY & $104-112$ & 1.2832 & $\begin{array}{c}\text { HLA-C*12:03,HLA-A*29:02,HLA- } \\
\text { A*01:01,HLA-B*15:02 }\end{array}$ & 0.35734 & $100.00 \%$ & NO & YES & NT \\
\hline SPRWYFYYL & $105-113$ & 0.7340 & $\begin{array}{c}\text { HLA-B*07:02,HLA-B*08:01,HLA- } \\
\text { B }^{*} 15: 02, \text { HLA-C*12:03 }\end{array}$ & 0.34101 & $100.00 \%$ & NO & NO & NT \\
\hline QRNAPRITF & $9-17$ & 0.4654 & $\begin{array}{c}\text { HLA-C*07:02,HLA-C*07:01,HLA- } \\
\text { B*15:02,HLA-C*06:02,HLA- } \\
\text { C*12:03, HLA-C*03:03,HLA- } \\
\text { C*14:02 }\end{array}$ & 0.21019 & $88.89 \%$ & NO & YES & NT \\
\hline DLSPRWYFY & $103-111$ & 1.7645 & $\begin{array}{c}\text { HLA-C*03:03,HLA-C*12:03,HLA- } \\
\text { A*29:02,HLA-C*07:02,HLA- } \\
\text { B*15:02,HLA-A*30:02 }\end{array}$ & 0.25933 & $88.89 \%$ & NO & YES & NT \\
\hline TWLTYTGAI & $329-337$ & 0.5439 & $\begin{array}{l}\text { HLA-C*14:02,HLA-C*03:03,HLA- } \\
\text { C*12:03 }\end{array}$ & 0.11986 & $88.89 \%$ & NO & NO & NT \\
\hline SSPDDQIGY & $78-86$ & 0.5260 & $\begin{array}{l}\text { HLA-C*12:03,HLA-C*07:01,HLA- } \\
\text { C*14:02 }\end{array}$ & 0.06340 & $88.89 \%$ & NO & YES & NT \\
\hline
\end{tabular}


Table 2 (on next page)

Results of docking studies

Table 2: Results of docking studies performed using HADDOCK 2.4 with selected T cell epitopes and corresponding HLA molecules 
Table: $\mathbf{2}$

\begin{tabular}{|c|c|c|c|c|c|c|c|c|}
\hline \multirow[b]{2}{*}{ PDB id } & \multicolumn{5}{|c|}{ MHC-1 } & \multicolumn{3}{|c|}{ MHC-2 } \\
\hline & 5VGE & 5VGE & 6J1W & $5 \mathrm{VWH}$ & $3 \times 13$ & 2FSE & 2FSE & 5LAX \\
\hline HLA molecule & HLA-C*07:02 & HLA-C*07:02 & HLA-A*30:01 & HLA-B*58:01 & HLA-B*08:01 & HLA-DRB1*01:01 & HLA-DRB1*01:01 & $\begin{array}{c}\text { HLA- } \\
\text { DRB1*04:01 }\end{array}$ \\
\hline Epitope & PYRVVVLSF & QLTPTWRVY & HVTFFIYNK & LTWICLLQF & SPRWYFYYL & $\begin{array}{c}\text { TNGVGYQPYRVV } \\
\text { VLS } \\
\end{array}$ & $\begin{array}{c}\text { ITLKKRWQLALSKG } \\
\text { V }\end{array}$ & $\begin{array}{c}\text { LFLTWICLLQFAY } \\
\text { AN } \\
\end{array}$ \\
\hline $\begin{array}{l}\text { HADDOCK } \\
\text { score }\end{array}$ & $-30.4+/-7.5$ & $-8.5+/-5.3$ & $-65.5+/-7.7$ & $-10.7+/-1.0$ & $-29.3+/-3.2$ & $-38.1+/-9.9$ & $-23.5+/-8.5$ & $-78.4+/-10.7$ \\
\hline Cluster size & 13 & 38 & 44 & 105 & 84 & 8 & 4 & 57 \\
\hline $\begin{array}{l}\text { RMSD from the } \\
\text { overall } \\
\text { lowest-energy } \\
\text { structure }\end{array}$ & $2.4+/-0.1$ & $0.5+/-0.3$ & $0.5+/-0.3$ & $1.5+/-0.2$ & $0.6+/-0.4$ & $0.8+/-0.5$ & $0.4+/-0.3$ & $0.5+/-0.3$ \\
\hline $\begin{array}{c}\text { Van der Waals } \\
\text { energy }\end{array}$ & $-46.6+/-4.5$ & $-58.8+/-8.1$ & $-64.5+/-6.3$ & $-52.2+/-3.4$ & $-62.4+/-4.9$ & $-65.7+/-4.1$ & $-52.2+/-4.6$ & $-74.9+/-7.2$ \\
\hline $\begin{array}{c}\text { Electrostatic } \\
\text { energy }\end{array}$ & $\begin{array}{c}-199.1+/- \\
10.1 \\
\end{array}$ & $-72.7+/-27.1$ & $\begin{array}{c}-269.7+/- \\
30.4 \\
\end{array}$ & $-41.7+/-9.2$ & $\begin{array}{c}-158.1+/- \\
11.5 \\
\end{array}$ & $-81.1+/-24.4$ & $-157.7+/-51.4$ & $-48.0+/-6.7$ \\
\hline $\begin{array}{c}\text { Desolvation } \\
\text { energy }\end{array}$ & $-29.7+/-0.8$ & $-20.8+/-1.3$ & $-44.8+/-3.1$ & $-37.6+/-2.7$ & $-45.8+/-3.3$ & $-19.3+/-1.1$ & $-14.9+/-2.2$ & $-60.4+/-2.1$ \\
\hline $\begin{array}{l}\text { Restraints } \\
\text { violation } \\
\text { energy }\end{array}$ & $\begin{array}{l}856.7+/- \\
73.0\end{array}$ & $\begin{array}{l}856.5+/- \\
33.6\end{array}$ & $\begin{array}{l}977.1+/- \\
59.8\end{array}$ & $\begin{array}{c}875.0+/- \\
34.7\end{array}$ & $\begin{array}{c}1105.8+/- \\
27.7\end{array}$ & $632.2+/-117.2$ & $752.0+/-91.9$ & $664.6+/-44.5$ \\
\hline $\begin{array}{c}\text { Buried Surface } \\
\text { Area }\end{array}$ & $\begin{array}{c}1803.4+/- \\
49.8\end{array}$ & $\begin{array}{c}1575.6+/- \\
86.2\end{array}$ & $\begin{array}{c}1840.6+/- \\
27.6\end{array}$ & $\begin{array}{c}1471.4+/- \\
47.3\end{array}$ & $\begin{array}{c}1612.3+/- \\
51.2\end{array}$ & $1681.7+/-49.6$ & $1722.6+/-47.8$ & $1985.6+/-17.1$ \\
\hline Z-Score & -1.2 & -1.3 & -1.8 & -1.4 & -2.1 & -2.2 & -1.4 & -1.6 \\
\hline
\end{tabular}


Table 3 (on next page)

Linear B-cell epitopes of SARS-CoV-2

Table-3 (a): Linear B-cell epitopes from structural proteins of SARS-CoV-2 predicted by BepiPred-2.0 (b) Linear B-cell epitopes from structural proteins of SARSCoV-2 predicted by LBtope. The highlighted epitopes are the best epitopes and promising vaccine candidates. 


\section{Table-3a}

\begin{tabular}{|c|c|c|c|c|c|c|}
\hline \multicolumn{7}{|c|}{ Surface glycoprotein } \\
\hline \multirow[t]{2}{*}{ B-cell epitopes } & \multirow[t]{2}{*}{ Position } & \multirow{2}{*}{$\begin{array}{l}\text { Antigenicity } \\
\text { score }\end{array}$} & \multirow[t]{2}{*}{ Conservancy } & \multirow[t]{2}{*}{ Toxicity } & \multicolumn{2}{|c|}{ Allergenicity } \\
\hline & & & & & $\begin{array}{c}\text { AllerTOP } \\
2.0 \\
\end{array}$ & $\begin{array}{c}\text { AllergenFP } \\
1.0 \\
\end{array}$ \\
\hline GQSKRVDFC & $1035-1043$ & 1.779 & $100.00 \%$ & NT & YES & YES \\
\hline NSASFSTFKCYGVSPTKLNDLCFTNV & 370-395 & 1.3609 & $84.62 \%$ & NT & NO & NO \\
\hline GDEVRQIAPGQTGKIADYNYK & $404-424$ & 1.3212 & $90.48 \%$ & NT & YES & YES \\
\hline VNCTEVP & $615-621$ & 1.129 & $71.43 \%$ & NT & YES & YES \\
\hline NNLDSKVGGNYNY & $439-451$ & 0.9437 & $53.85 \%$ & NT & YES & NO \\
\hline DLEGKQGNFKNLRE & $178-191$ & 0.9256 & $64.29 \%$ & NT & YES & NO \\
\hline VEAEVQI & $987-993$ & 0.8205 & $100.00 \%$ & NT & YES & YES \\
\hline QCVNLTTRTQLPPAYTNSFTRGV & $14-36$ & 0.7515 & $26.09 \%$ & NT & YES & NO \\
\hline FSNVTWFHAIHVSGTNGTKRFDN & $59-81$ & 0.6767 & $39.13 \%$ & NT & YES & YES \\
\hline YLTPGDSSSGWTA & $248-260$ & 0.627 & $38.46 \%$ & NT & NO & NO \\
\hline AYTMSLGAENSVAYSN & 694-709 & 0.6003 & $81.25 \%$ & NT & YES & NO \\
\hline VEGFNCYFPLQ & $483-493$ & 0.5612 & $45.45 \%$ & NT & YES & YES \\
\hline VNNSYECDIP & $656-665$ & 0.5327 & $80.00 \%$ & NT & NO & YES \\
\hline LGVYYHKNNKSWMESEFRVYSSA & $141-163$ & 0.4829 & $21.74 \%$ & NT & NO & YES \\
\hline FYEPQIITTD & 1109-1118 & 0.4179 & $80.00 \%$ & NT & YES & YES \\
\hline \multicolumn{7}{|c|}{ orf3a protein } \\
\hline \multirow[t]{2}{*}{ B-cell epitopes } & \multirow[t]{2}{*}{ Position } & \multirow{2}{*}{$\begin{array}{l}\text { Antigenicity } \\
\text { score }\end{array}$} & \multirow[t]{2}{*}{ Conservancy } & \multirow[t]{2}{*}{ Toxicity } & \multicolumn{2}{|c|}{ Allergenicity } \\
\hline & & & & & $\begin{array}{c}\text { AllerTOP } \\
2.0 \\
\end{array}$ & $\begin{array}{c}\text { AllergenFP } \\
1.0 \\
\end{array}$ \\
\hline QGEIKDATPSDF & $17-28$ & 1.1542 & $33.33 \%$ & NT & YES & NO \\
\hline KIITLKKRWQL & $61-71$ & 1.0171 & $81.82 \%$ & NT & $\mathrm{NO}$ & YES \\
\hline \multicolumn{7}{|c|}{ Envelope protein } \\
\hline B-cell epitopes & Position & $\begin{array}{l}\text { Antigenicity } \\
\text { score }\end{array}$ & Conservancy & Toxicity & \multicolumn{2}{|c|}{ Allergenicity } \\
\hline
\end{tabular}




\begin{tabular}{|c|c|c|c|c|c|c|}
\hline YVYSRVKNLNSSRVP & $57-71$ & 0.4492 & $80.00 \%$ & NT & NO & NO \\
\hline \multicolumn{7}{|c|}{ membrane glycoprotein } \\
\hline \multirow[t]{2}{*}{ B-cell epitopes } & \multirow[t]{2}{*}{ Position } & \multirow{2}{*}{$\begin{array}{l}\text { Antigenicity } \\
\text { score }\end{array}$} & \multirow[t]{2}{*}{ Conservancy } & \multirow[t]{2}{*}{ Toxicity } & \multicolumn{2}{|c|}{ Allergenicity } \\
\hline & & & & & $\begin{array}{c}\text { AllerTOP } \\
2.0\end{array}$ & $\begin{array}{c}\text { AllergenFP } \\
1.0\end{array}$ \\
\hline KLGASQRVAGDS & $180-191$ & 0.0439 & $83.33 \%$ & NT & NO & NO \\
\hline RYRIGNYKLNTDHSSSSDNIA & $198-218$ & 0.1635 & $85.71 \%$ & NT & NO & YES \\
\hline \multicolumn{7}{|c|}{ orf6 protein } \\
\hline \multirow[t]{2}{*}{ B-cell epitopes } & \multirow[t]{2}{*}{ Position } & \multirow{2}{*}{$\begin{array}{l}\text { Antigenicity } \\
\text { score }\end{array}$} & \multirow[t]{2}{*}{ Conservancy } & \multirow[t]{2}{*}{ Toxicity } & \multicolumn{2}{|c|}{ Allergenicity } \\
\hline & & & & & $\begin{array}{c}\text { AllerTOP } \\
2.0\end{array}$ & $\begin{array}{c}\text { AllergenFP } \\
1.0\end{array}$ \\
\hline LTENKYSQLDEEQP & $44-57$ & 0.5866 & $57.14 \%$ & NT & YES & YES \\
\hline \multicolumn{7}{|c|}{ nucleocapsid phosphoprotein } \\
\hline \multirow[t]{2}{*}{ B-cell epitopes } & \multirow[t]{2}{*}{ Position } & \multirow{2}{*}{$\begin{array}{c}\text { Antigenicity } \\
\text { score }\end{array}$} & \multirow[t]{2}{*}{ Conservancy } & \multirow[t]{2}{*}{ Toxicity } & \multicolumn{2}{|c|}{ Allergenicity } \\
\hline & & & & & $\begin{array}{c}\text { AllerTOP } \\
2.0 \\
\end{array}$ & $\begin{array}{c}\text { AllergenFP } \\
1.0 \\
\end{array}$ \\
\hline HGKEDLKFPRGQGVPINTNSSPDDQIGYYRRATRRIRGGDGKMKDLS & $59-105$ & 0.5773 & $89.36 \%$ & NT & NO & NO \\
\hline TLPKGFYAEGSRGGSQASSRSSSRSRNSSRNSTPGSSRGTSPARMAGNGGD & $166-216$ & 0.5064 & $88.24 \%$ & NT & NO & YES \\
\hline LNQLESKMSGKGQQQQGQTVTKKSAAEASKKPRQKRTATK & $227-266$ & 0.5387 & $97.50 \%$ & NT & NO & NO \\
\hline RRGPEQTQGNFGDQELIRQGTDYK & $276-299$ & 0.6277 & $95.83 \%$ & NT & NO & YES \\
\hline
\end{tabular}

2

3

\section{Table-3b}

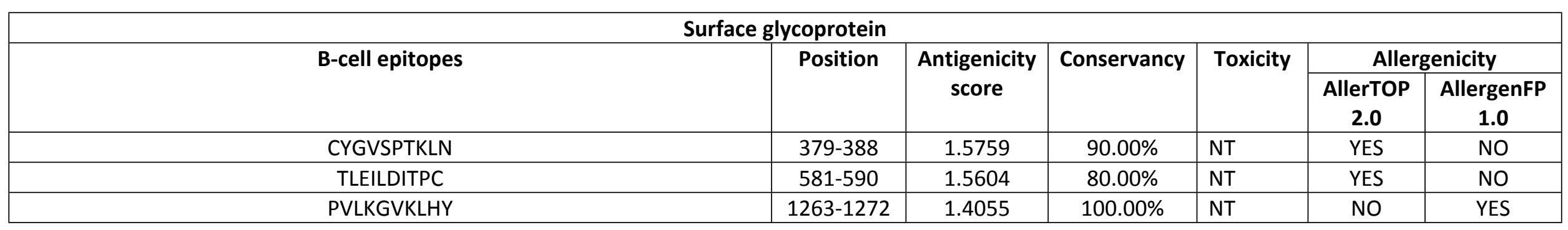




\begin{tabular}{|c|c|c|c|c|c|c|}
\hline AGAAAYYVGYLQPRT & $260-274$ & 0.9134 & $66.67 \%$ & NT & NO & NO \\
\hline GFQPTNGVGYQPYRVVVLSF & $496-515$ & 0.8857 & $80.00 \%$ & NT & YES & NO \\
\hline PFLGVYYHKNNKSW & $139-152$ & 0.7487 & $28.57 \%$ & NT & NO & NO \\
\hline PINLVRDLPQGFSALEPLVDLPIGI & $209-233$ & 0.6961 & $60.00 \%$ & NT & YES & NO \\
\hline PLSETKCTLKSFT & $295-307$ & 0.6582 & $61.54 \%$ & NT & YES & NO \\
\hline RARSVASQ & $683-690$ & 0.6389 & $37.50 \%$ & NT & NO & NO \\
\hline KVGGNYNYL & $444-452$ & 0.5994 & $55.56 \%$ & NT & YES & YES \\
\hline VFLVLLPLVSSQCVN & $03--17$ & 0.5954 & $33.33 \%$ & NT & NO & NO \\
\hline KKSTNLVKNKCV & $528-539$ & 0.5949 & $66.67 \%$ & TOXIN & YES & NO \\
\hline IQDSLSSTASALGK & $934-947$ & 0.5193 & $64.29 \%$ & NT & YES & NO \\
\hline SQPFLMDL & $172-179$ & 0.4797 & $50.00 \%$ & NT & YES & YES \\
\hline \multicolumn{7}{|c|}{ orf3a protein } \\
\hline \multirow[t]{2}{*}{ B-cell epitopes } & \multirow[t]{2}{*}{ Position } & \multirow{2}{*}{$\begin{array}{l}\text { Antigenicity } \\
\text { score }\end{array}$} & \multirow[t]{2}{*}{ Conservancy } & \multirow[t]{2}{*}{ Toxicity } & \multicolumn{2}{|c|}{ Allergenicity } \\
\hline & & & & & $\begin{array}{c}\text { AllerTOP } \\
2.0\end{array}$ & $\begin{array}{c}\text { AllergenFP } \\
1.0\end{array}$ \\
\hline EIKDATPSDF & $19-28$ & 1.5094 & $40.00 \%$ & NT & YES & NO \\
\hline WKCRSKNPLL & $131-140$ & 1.2111 & $90.00 \%$ & TOXIN & YES & NO \\
\hline \multicolumn{7}{|c|}{ Envelope protein } \\
\hline \multirow[t]{2}{*}{ B-cell epitopes } & \multirow[t]{2}{*}{ Position } & \multirow{2}{*}{$\begin{array}{l}\text { Antigenicity } \\
\text { score }\end{array}$} & \multirow[t]{2}{*}{ Conservancy } & \multirow[t]{2}{*}{ Toxicity } & \multicolumn{2}{|c|}{ Allergenicity } \\
\hline & & & & & $\begin{array}{c}\text { AllerTOP } \\
2.0\end{array}$ & $\begin{array}{c}\text { AllergenFP } \\
1.0 \\
\end{array}$ \\
\hline YVYSRVKNLNSSRVP & $57-71$ & 0.4492 & $72.22 \%$ & NO & NO & NO \\
\hline \multicolumn{7}{|c|}{ membrane glycoprotein } \\
\hline \multirow[t]{2}{*}{ B-cell epitopes } & \multirow[t]{2}{*}{ Position } & \multirow{2}{*}{$\begin{array}{l}\text { Antigenicity } \\
\text { score }\end{array}$} & \multirow[t]{2}{*}{ Conservancy } & \multirow[t]{2}{*}{ Toxicity } & \multicolumn{2}{|c|}{ Allergenicity } \\
\hline & & & & & $\begin{array}{c}\text { AllerTOP } \\
2.0 \\
\end{array}$ & $\begin{array}{c}\text { AllergenFP } \\
1.0 \\
\end{array}$ \\
\hline ITVATSRTLSYYKLGASQR & $168-186$ & 0.7666 & $100.00 \%$ & NT & NO & YES \\
\hline SDNIALL & $214-219$ & 0.4677 & $85.71 \%$ & NT & NO & YES \\
\hline \multicolumn{7}{|c|}{ orf6 protein } \\
\hline \multirow[t]{2}{*}{ B-cell epitopes } & \multirow[t]{2}{*}{ Position } & \multirow{2}{*}{$\begin{array}{l}\text { Antigenicity } \\
\text { score }\end{array}$} & \multirow[t]{2}{*}{ Conservancy } & \multirow[t]{2}{*}{ Toxicity } & \multicolumn{2}{|c|}{ Allergenicity } \\
\hline & & & & & $\begin{array}{c}\text { AllerTOP } \\
2.0\end{array}$ & $\begin{array}{c}\text { AllergenFP } \\
1.0\end{array}$ \\
\hline FHLVDFQVTI & $02--11$ & 1.8174 & $100.00 \%$ & NT & YES & NO \\
\hline
\end{tabular}




\begin{tabular}{|c|c|c|c|c|c|c|}
\hline SKSLTENKYSQLDEEQPME & $41-59$ & 0.4682 & $57.89 \%$ & NT & NO & NO \\
\hline \multicolumn{7}{|c|}{ nucleocapsid phosphoprotein } \\
\hline \multirow[t]{2}{*}{ B-cell epitopes } & \multirow[t]{2}{*}{ Position } & \multirow{2}{*}{$\begin{array}{l}\text { Antigenicity } \\
\text { score }\end{array}$} & \multirow[t]{2}{*}{ Conservancy } & \multirow[t]{2}{*}{ Toxicity } & \multicolumn{2}{|c|}{ Allergenicity } \\
\hline & & & & & $\begin{array}{c}\text { AllerTOP } \\
2.0\end{array}$ & $\begin{array}{c}\text { AllergenFP } \\
1.0\end{array}$ \\
\hline DNGPQNQRNAPRITFGGP & $3--20$ & 0.4751 & $66.67 \%$ & NT & NO & NO \\
\hline GERSGARSKQRRPQGL & $29-45$ & 0.5789 & $81.25 \%$ & NT & NO & NO \\
\hline DLKFPRGQGVPINTNSSPDDQIGYYRRATRRIRGGDGKMKDLSPRWYFYYL & $63-113$ & 0.6372 & $90.20 \%$ & NT & NO & YES \\
\hline DPNFKDQV & $343-350$ & 1.7958 & $75.00 \%$ & NT & YES & YES \\
\hline
\end{tabular}

